\title{
The Role of Weather Radar in Rainfall Estimation and Its Application in Meteorological and Hydrological Modelling-A Review
}

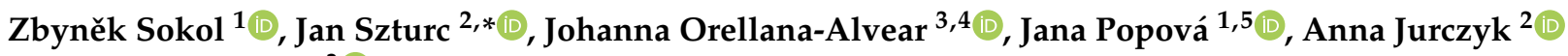 \\ and Rolando Célleri ${ }^{3}$ (i) \\ 1 Institute of Atmospheric Physics of the Czech Academy of Sciences, Bocni II, 14100 Praha 4, Czech Republic; \\ sokol@ufa.cas.cz (Z.S.); popova@ufa.cas.cz (J.P.) \\ 2 Institute of Meteorology and Water Management-National Research Institute, PL 01-673 Warsaw, Poland; \\ anna.jurczyk@imgw.pl \\ 3 Departamento de Recursos Hídricos y Ciencias Ambientales and Facultad de Ingeniería, \\ Universidad de Cuenca, Cuenca EC10207, Ecuador; johanna.orellana@ucuenca.edu.ec (J.O.-A.); \\ rolando.celleri@ucuenca.edu.ec (R.C.) \\ 4 Laboratory for Climatology and Remote Sensing (LCRS), Faculty of Geography, University of Marburg, \\ D-035032 Marburg, Germany \\ 5 Faculty of Science, Charles University, Albertov 6, 12800 Praha 2, Czech Republic \\ * Correspondence: jan.szturc@imgw.pl
}

\section{check for}

updates

Citation: Sokol, Z.; Szturc, J.; Orellana-Alvear, J.; Popová, J.; Jurczyk, A.; Célleri, R. The Role of Weather Radar in Rainfall Estimation and Its Application in Meteorological and Hydrological Modelling-A Review. Remote Sens. 2021, 13, 351. https://doi.org/10.3390/rs13030351

Academic Editor: Joan Bech Received: 27 November 2020 Accepted: 17 January 2021 Published: 20 January 2021

Publisher's Note: MDPI stays neutral with regard to jurisdictional claims in published maps and institutional affiliations.

Copyright: (c) 2021 by the authors Licensee MDPI, Basel, Switzerland. This article is an open access article distributed under the terms and conditions of the Creative Commons Attribution (CC BY) license (https:// creativecommons.org/licenses/by/ $4.0 /)$

\begin{abstract}
Radar-based rainfall information has been widely used in hydrological and meteorological applications, as it provides data with a high spatial and temporal resolution that improve rainfall representation. However, the broad diversity of studies makes it difficult to gather a condensed overview of the usefulness and limitations of radar technology and its application in particular situations. In this paper, a comprehensive review through a categorization of radar-related topics aims to provide a general picture of the current state of radar research. First, the importance and impact of the high temporal resolution of weather radar is discussed, followed by the description of quantitative precipitation estimation strategies. Afterwards, the use of radar data in rainfall nowcasting as well as its role in preparation of initial conditions for numerical weather predictions by assimilation is reviewed. Furthermore, the value of radar data in rainfall-runoff models with a focus on flash flood forecasting is documented. Finally, based on this review, conclusions of the most relevant challenges that need to be addressed and recommendations for further research are presented. This review paper supports the exploitation of radar data in its full capacity by providing key insights regarding the possibilities of including radar data in hydrological and meteorological applications.
\end{abstract}

Keywords: hydrological modelling; nowcasting; QPE; flash floods; weather radar

\section{Introduction}

Radar technology (an active instrument that operates in a microwave band) was intensively developed for military use in the period before and during World War II. During the war, radar operators noticed echoes on radar screens caused by weather phenomena. After the war, scientists studied how to use radars for detecting precipitation. Since then, weather radars have been used by national weather services and research institutions, since they enable the detection of precipitating clouds, as well as their structure and development. Considerable efforts have also been made to obtain more accurate quantitative precipitation information that can be used in hydrological modelling and numerical weather prediction.

The use of radar-based rainfall data for hydrological modelling was motivated by the need to accurately measure the spatial structure of precipitation fields and to exploit the potential of radar-based rainfall data to generate short-term and very short-term (near real-time) quantitative precipitation forecasts. One of the first uses of weather radar 
precipitation data in hydrological applications was as an input to rainfall-runoff models. Therefore, effective derivation of precipitation from radar retrievals has been a subject of interest from the beginning of radar meteorology and hydrology and still remains one of the most important areas of research.

In terms of the estimation of quantitative precipitation, the well-known MarshallPalmer formula [1] for converting radar reflectivity into precipitation intensity is still often used today. It is one of the most cited papers in the field of radar hydrology. The literature on this topic is extensive, and various reviews exist, e.g., Wilk and Kessler [2], Wilson and Brandes [3], Zawadzki [4], Joss and Waldvogel [5], and Krajewski and Smith [6].

Other areas of application of weather radar networks in operational hydrology include storm hazard assessment and flood forecasting, warning, and management $[7,8]$. The current interest in land surface hydrological processes has stimulated research into the spatial and temporal variability of precipitation. A potential area for the application of weather radar in this context is in the validation and verification of sub-grid rainfall parameterizations for atmospheric mesoscale models and global circulation models [9].

Weather radar measurements are obviously connected with non-negligible and sometimes even large errors; hence, radar can be referred to as a semi-quantitative measurement device [10]. The errors are due to measuring techniques and their extent depends on weather conditions, in particular on precipitation processes and the size distribution of precipitation particles. Nevertheless, radar provides very useful information, i.e., realtime coverage at high spatiotemporal resolution, with data being available after a very short time from being observed. Thus, the quality control procedures can be carried out simultaneously for a proper quantitative precipitation estimation.

The main purpose of this review paper is to provide a concise description of the current state of research in the field of the use of weather radars in meteorology and hydrology with particular attention paid to its use for hydrological modelling and applications. Data from meteorological radars are used both for the analysis of current precipitation, which directly enters the hydrological models, and for the forecast of precipitation. Moreover, prognostic precipitation is also an important input to hydrological models. Therefore, in this review paper, we also discuss precipitation nowcasting and radar data assimilation into numerical weather prediction (NWP) models, because short-term precipitation forecasts by these models can be used to prepare inputs to hydrological models. This paper is organized as follows: Section 2 shows the importance of the use of weather radar data for hydrological applications with a particular regard to temporal and spatial resolutions of the data, while Section 3 covers the topics that are related to quantitative precipitation estimation (QPE) using not only weather radar data. Section 4 discusses the use of the weather radar data to generate nowcasts (i.e., very short-term forecasts), while Section 5 describes the role of weather radars in numerical mesoscale meteorological models. Section 6 presents weather radar-based precipitation in terms of its use in hydrological rainfall-runoff models, mostly for flash flood forecasting, and finally Section 7 provides a summary and draws conclusions.

\section{The Importance of Rainfall Input for Hydrological Modelling}

\subsection{Spatial and Temporal Resolution of Weather Radar and Rain Gauge Data}

Precipitation is the main input for the hydrological cycle and its quantitative modelling. However, precipitation is extremely difficult to measure accurately due to its intermittent nature, spatiotemporal variability, and sensitivity to environmental conditions [11]. These characteristics become even more difficult to measure over the mountainous regions. Rain gauges are the most used devices for in-situ point measurements of precipitation intensity and duration if they measure these values by telemetry. What is very important from the hydrological point of view is that rain gauges accumulate rainfall continuously over a time period of interest. Nevertheless, rain gauges poorly estimate areal rainfall due to their sparse distribution, particularly in regions that have high spatial variability, such as mountain ranges. 
Weather radars are remote sensing equipment that are widely employed in the hydrological and meteorological communities for the estimation of areal precipitation at high spatial and temporal resolution. The analysis of spatial and temporal characteristics of a given storm event, especially its velocity and temporal changeability, as well as catchment dimensions, indicates the minimum requirements in terms of temporal and spatial resolutions of rainfall data for a given storm cell. Weather radars can almost instantaneously provide precipitation estimates with high temporal resolution after they have been transformed from radar reflectivity data. The highest temporal resolutions achievable for short-range (local) radars, used especially in urban areas, are about 1-min with a very simplified scanning strategy limited to the lowest angles of elevation. However, the precipitation intensity derived from weather radar data in the case of employing a standard scan strategy (usually with a temporal resolution of about 5-min) often neglects the high variability of temporal precipitation, especially for short-duration rainfall events.

When compared to weather radars, which scan the atmosphere over a volume whose projected area is roughly $1 \mathrm{~km}^{2}$ for a standard C-band radar, a rain gauge typically collects rainfall at ground level over a circular area with a diameter of $20 \mathrm{~cm}$. Hence, observation scales differ dramatically between these two devices. As a consequence, direct comparison of the outputs of a rain gauge and weather radar is problematic at least [12].

Many investigations have incorporated rain gauge data either in quality control of weather radar data or in combination with radar precipitation estimates, resulting in highresolution merged products that have higher accuracy than rain gauge data or weather radar data alone. However, constraints in the reliable estimation of "true rainfall" still exist due to differences in spatial and temporal variability between rain gauges and radar estimates [13].

\subsection{Needs of Urban Hydrology in Terms of Resolution of Precipitation Data}

The small size of urban catchments and the intended hydrological applications (especially in real time) require information about precipitation at small temporal and spatial scales from 1 to $10 \mathrm{~min}$ and from 1 to a few $\mathrm{km}$, respectively [14]. Typical national or regional precipitation networks often perform rainfall monitoring at lower resolutions, which results in an underestimation of precipitation in storms. Therefore, specific hydrometeorological networks devoted to urban hydrology should be built. Many authors have described and quantified the requirements of temporal and spatial resolutions of rainfall data for their use in urban hydrology (including Berne et al. [15], Emmanuel et al. [16], Ochoa-Rodriguez et al. [17], de Vos et al. [14], or Thorndahl et al. [18]).

Berne et al. [15] investigated in detail the temporal and spatial resolution of rain measurements relevant for urban hydrology. A catchment can be seen as a system that integrates a main input (rainfall) and produces a time series output (discharge). The characteristic time associated with such a system defines its temporal dynamics and the temporal scale determines the minimum time resolution needed for the input signal to avoid smoothing of the system response:

$$
\Delta t=\frac{t_{l}}{f}
$$

where $\Delta t$ is the time resolution [min] and $t_{l}$ is the characteristic time of the system [min]. The factor $f$ (Berne et al. [15] suggested $f=4$ in their study) is an order of magnitude and depends on a given catchment and expected accuracy.

The characteristic time of a catchment can be assessed using its response to a pulse input of rainfall. Among the different approaches used to define the hydrological characteristic time of a basin, the lag time $\left(t_{l}\right)$ - the time difference between the gravity center of the mean rainfall over the catchment and the gravity center of the generated hydrograph-is often selected. 
Based on data from a set of catchments, an empirical formula for the relationship between the lag time $t_{l}(\mathrm{~min})$ and a catchment area $A\left(\mathrm{~km}^{2}\right)$ can be estimated. According to Berne et al. [15]:

$$
t_{l}=3 \cdot A^{0.3}
$$

By studying the temporal and spatial structure of rainfall on a small scale in Mediterranean climates (using a geostatistical method and investigating the impact of time averaging), Berne et al. [15] proposed an empirical formula for the required temporal resolution, $\Delta t$, estimated for urban hydrology:

$$
\Delta t=0.75 \cdot A^{0.3}
$$

and an empirical formula for the required spatial resolution, $\Delta x$ :

$$
\Delta x=1.5 \cdot \sqrt{\Delta t}
$$

Figure 1 schematically depicts the relationship between required temporal resolution $\Delta t$ and catchment area $A$.

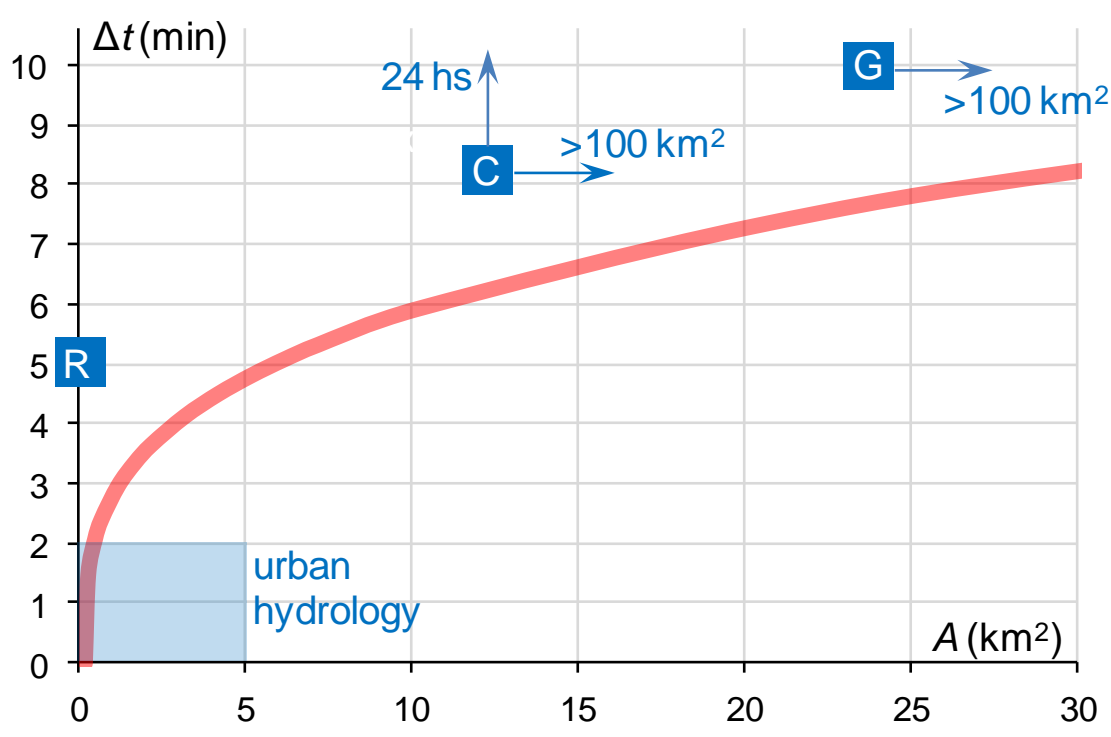

Figure 1. The relationship between required temporal resolution of precipitation data and catchment area (based on Berne et al. [15] et de Vos [14]). The light blue rectangle represents the required resolution for urban catchments, while the dark blue squares represent the most common resolutions of standard measurement techniques: $\mathrm{R}$-weather radar network; G-recording rain gauge network; and $\mathrm{C}-$ manual rain gauge network. The blue arrows indicate the actual positions of the blue squares, symbolizing the particular measurement techniques in relation to the diagram scale.

The accuracy of rainfall inputs is often a limitation in urban and mountain hydrology, because the temporal and spatial resolutions of rainfall data required for urban applications exceed those needed for rural catchments. Despite the improvements in rainfall measurement techniques and the development of urban rain gauge networks, it is still very difficult to retrieve details on rainfall variability at the temporal and spatial scales useful for urban hydrology, particularly for rain events of the convective type [16]. Urban catchments are characterized by a high proportion of impervious surfaces, and this leads to a large fraction of rainfall-producing direct runoff and a fast hydrological response. This makes cities especially vulnerable to flooding.

Ochoa-Rodriguez et al. [17] evaluated the required spatial and temporal resolutions of rainfall in a simple spatiotemporal scaling framework. A spatial resolution of $1 \mathrm{~km}$, typically used in weather radars, was found adequate for hydrodynamic model results, although some extremes were missed. A temporal resolution of $5 \mathrm{~min}$, which is currently 
available in most operational weather radar products, is sufficient. Nevertheless, the accuracy of 5-min radar data can be improved with the use of an accumulation procedure that assumes the constant velocity of the rainfall field and precipitation intensity to vary linearly in time between two consecutive time steps.

Reduced temporal resolution has more impact on the hydrological modelling accuracy than decreasing spatial resolution [12,19]. In the study by Yoon et al. [19], the root mean square error and correlation coefficient increased as the accumulated time and radar bin size increased, and the correlation coefficient was found to be much more sensitive to temporal resolution than spatial resolution. An assessment of the impact of the temporal resolution of rainfall data on rainfall-runoff modelling was performed by, among others, OchoaRodriguez et al. [17], who confirmed that the influence of temporal accumulation of radar rainfall data is higher than that of spatial resolution, especially in small drainage areas.

\section{High-Resolution Techniques for Precipitation Measurement and Estimation}

The estimation of a precipitation field on the ground presents one of the most difficult tasks in meteorology and hydrology [20]. Information about a given precipitation phenomenon can be derived from different types of measurement techniques, which are briefly described in this section. Each measurement technique has advantages and disadvantages; thus, there is a tendency, in terms of the estimation of a precipitation field, to use precipitation information derived from various measurement techniques.

For the estimation of precipitation - either precipitation intensity or accumulationsdata from the following measuring systems are used most often: a rain gauge network, a weather radar network, and a meteorological satellite (a passive instrument that uses visible and infrared channels). Other data sources, such as microwave links and crowdsourcing, are also used, but rather sporadically. Table 1 presents the general characteristics of these abovementioned three main techniques. All the data are associated with greater or lesser difficulties and are also burdened with errors of diverse structures, usually very difficult to diagnose and remove.

Table 1. Most frequent operational parameters of basic measurement techniques applied for the estimation of a precipitation field.

\begin{tabular}{cccc}
\hline Measurement Technique & Spatial Resolution & Temporal Resolution & $\begin{array}{c}\text { The Most Important Properties } \\
\text { for Combination }\end{array}$ \\
\hline Recording rain gauge network & $\begin{array}{c}\text { Point measurements } \\
\text { interpolated spatially }\end{array}$ & $1 \mathrm{~min}-1 \mathrm{~h}$ & $\begin{array}{c}\text { Measurements considered of relatively } \\
\text { high quality at gauge locations. }\end{array}$ \\
\hline Weather radar network & $0.5-2.0 \mathrm{~km}$ & $5-15 \mathrm{~min}$ & $\begin{array}{c}\text { Numerous measurement errors. Good } \\
\text { high-resolution reproduction of spatial } \\
\text { distribution of precipitation field. }\end{array}$ \\
$\begin{array}{c}\text { Meteorological satellite } \\
\text { Meteosat or GOES (VIS and } \\
\text { IR channels) }\end{array}$ & $\begin{array}{c}\text { About 4-6 km } \\
\text { (depending on latitude) }\end{array}$ & $5-15 \mathrm{~min}$ & $\begin{array}{c}\text { Low spatial resolution and } \\
\text { approximate measurements. Good } \\
\text { reprodion of location of clouds and } \\
\text { convective phenomena. High } \\
\text { data availability. }\end{array}$ \\
\hline
\end{tabular}

\subsection{Rain Gauge Networks}

Rain gauges measure point-wise precipitation with good accuracy, but their data suffer from systematic and random errors. The magnitude of measurement errors depends on many factors, including the weather conditions and physical processes, as well as the gauge type [21,22]. The precipitation accumulation during a current time period may be measured by manual or automatic rain gauges, such as a tipping bucket, weighing gauge, or optical gauge. In practice, due to financial limitations, a high measurement resolution of 1-10 min, although technically possible, is generally less frequent. 
The data measured by rain gauges are affected by different kinds of errors. Therefore, the data must be quality controlled at different levels of data processing and in real-time [23]. The commonly developed and implemented quality control (QC) procedures involve a few checks: gross errors, range check, temporal consistency check, spatial consistency check, and other source conformity checks (radar and satellite), as Otop et al. [24] and Jurczyk et al. [25] have noted.

The point-wise character of rain gauge measurements and the sparseness of operational networks make rain gauge measurements inadequate for providing sufficient information on the spatial distribution of precipitation. Therefore, rain gauge data are processed in order to provide 2D precipitation fields, once a quality control has been performed.

There are two main types of methods concerning the spatial interpolation of meteorological elements: deterministic and geostatistical. Deterministic interpolation methods include, among others, inverse distance weighting (IDW) [26], Thiessen polygons [27], and polynomial interpolation. In contrast, geostatistical interpolation methods implement spatial statistical models and give a direct opportunity for the evaluation of the estimation of errors [28,29]. The geostatistical interpolation methods are usually based on various versions of a Kriging algorithm, e.g., Ordinary Kriging, Universal Kriging, or Block Kriging, which employ a semi-variogram model, e.g., Gaussian, spherical, or exponential. The usefulness of the geostatistical methods depends on the nature of any analyzed meteorological situations and on the density and distribution of the measurement gauges, as well as their specific qualities.

\subsection{Weather Radar Networks}

\subsubsection{Introduction}

A weather radar transmits electromagnetic waves and measures the energy backscattered by the hydrometeors in the atmosphere, i.e., the radar reflectivity. Ground-based weather radars work mainly in three frequency bands: S, C, and X. Choice of the band for a particular location is made on the basis of a trade-off between the measuring range of reflectivity depending on the amount of signal attenuation and the cost of the radar. The advantages and disadvantages of the three bands are the following:

- $\quad$ S-band (2.7-2.9 GHz) is well suited for detecting heavy rain at very long ranges (up to $300 \mathrm{~km}$ ), as it is least affected by attenuation. However, quantitative precipitation estimation observations are reliable up to ranges of about $200 \mathrm{~km}$, as a larger beam width brings limitations. Data corrections are most robust and easiest to implement for S-band weather radars; however, they are also the most expensive.

- C-band (5.6-5.65 GHz) represents a compromise between range and reliability of reflectivity measurements and cost. A C-band weather radar can provide rain detection up to a range of $200 \mathrm{~km}$, but it is less expensive than an S-band radar. Attenuation of the received signal is significantly stronger than in case of an S-band radar. Thus, the attenuation limits the QPE to ranges of about 100-150 km.

- X-band (9.3-9.5 GHz) weather radars are more sensitive to hydrometeors than S- or $\mathrm{C}$-band weather radars when measuring up to a range of $50 \mathrm{~km}$. Attenuation of the signal by rain is strongest in the case of $\mathrm{X}$-band radars (compared to S- and C-band radars) and strongly limits the QPE. Accurate QPE is usually possible up to ranges of about $30 \mathrm{~km}$. On the other hand, X-band weather radars are the least expensive.

The radar reflectivity $(Z)$ can be converted to precipitation intensity $(R)$. Various empirical relationships, often called $Z-R$ equations, are used in the conversion of $Z$ into $R$.

$$
R\left[\mathrm{~mm} \cdot \mathrm{h}^{-1}\right]=\left(\frac{10^{\frac{\mathrm{Z}[\mathrm{dBZ}]}{10}}}{a}\right)^{\frac{1}{b}}
$$

where the $a$ and $b$ are constants that are experimentally determined, although they are not really constant, since they are related to particle size distribution of hydrometeors in 
the atmosphere. Particle size distribution varies with the type and phase of precipitation (solid or liquid), so different $Z-R$ relationships are determined corresponding to different precipitation types and drop size distributions. The $Z-R$ relationship also depends on local geographic conditions: location, altitude, and spatial exposition in particular [30].

High-quality QPE over a large area at high temporal and spatial resolution is important for many hydrological and meteorological purposes. In addition to rain gauges that have their own limitations, weather radars play an increasingly important role in QPE in the field of urban hydrology (e.g., [18]) or hydrological modelling of flash floods in mountainous areas. An advantage of weather radars is that they provide 3D observations at high temporal resolution and also cover a large area [31].

\subsubsection{Sources of Errors in Weather Radar Data}

Radar observations provide very good spatial representation of precipitation but are burdened with a wide spectrum of errors arising from different sources. The sources of errors are characterized by specific properties and spatial and temporal structures. Therefore, quality control aiming at the removal of detected errors and the quantitative characterization of data uncertainty is a crucial task in radar data processing. A review of the different sources of uncertainty can be found in numerous papers, such as Meischner [32], Michelson et al. [33], Villarini and Krajewski [34], Ośródka et al. [35].

Errors in weather radar data can be divided into several groups. The first group are hardware errors. These errors are related to the instability of electronics, antenna accuracy, and quality of signal processing [36]. The second group is related to radar beam geometry and scan strategy and includes effects related to increasing distance from the radar site, such as beam broadening and a greater distance between consecutive bins, i.e., measurement points [35]. Regarding the increasing distance from the radar site, there is an additional source of uncertainty, which is that with the increasing distance from the radar site, the radar beam gets farther from the Earth's surface because of the curvature and topography of the planet $[37,38]$.

The third group of errors in weather radar data is that the data contain echoes from non-meteorological targets. This influences the QPE to the highest degree. The echoes are mainly caused by (i) ground clutter (echoes from high objects close to the radar site, including wind farms) [39-41]; (ii) electromagnetic interference with the sun or external microwave emitters, which are usually visible in a radar image in the form of spikes pointing towards the radar site [42]; (iii) speckles caused by measurement noise; and (iv) biological objects, such as birds or insects [43].

Other groups of errors result from (i) beam blockage on terrain (i.e., mountains) resulting in a decrease of radar signal [44,45]; (ii) attenuation of the signal by rain, especially by heavy rain [46]; and (iii) anomalous propagation of the radar beam due to specific atmospheric temperature gradient, which causes a part of the beam to be propagated along a non-normal path - this generates return signals to the radar from distances further than in normal conditions $[41,47,48]$.

Each category of errors is corrected by a dedicated quality control technique, usually very specific to the site and the given radar manufacturer, and, as a consequence, is characterized by individual quality indices. The total quality is qualitatively or quantitatively computed by aggregation of all the indices into one total quality index $(Q I)$ by using a multiplicative scheme [49]. Besides QI, flags describing particular detected errors can be employed. In this case, fields of radar data quality are assigned to each radar precipitation product.

It should be emphasized that the quality of the radar data is still reduced even when the correction of the radar data has been performed and leads to an improvement in data. This reduced quality of radar data is due to the fact that each correction of errors leaves some uncertainty in the final data [34].

The quality control of raw three-dimensional (3D) data volumes of the radar reflectivity is most often performed by dedicated systems, which are developed by particular national 
meteorological services, like RADVOL-QC [35], or by supranational institutions like the EUMETNET OPERA program [50,51] or BALTRAD program [52].

\subsubsection{Dual-Polarization Weather Radars}

In dual-polarization (hereafter dual-pol) weather radars, the transmission and reception of pulses of energy are both horizontally and vertically orientated $\left(Z_{H}\right.$ and $Z_{V}$, respectively). As a consequence, information on horizontal and vertical dimensions of meteorological targets, such as their shape and size, may be inferred from dual-pol radar measurements. They also give the radar reflectivity and Doppler velocity, just like single polarimetric radars.

Most frequently, the following dual-pol products are studied: differential reflectivity $\left(Z_{D R}\right)$, specific differential phase shift $\left(K_{D P}\right)$, and sometimes correlation coefficient $\left(\rho_{H V}\right)$. Since the advent of dual-pol radar technology, many studies have been conducted to determine the extent to which the dual-pol products add benefits to estimating $R$ as compared to $Z$ alone [6].

The $Z_{D R}$ allows for the discrimination of hydrometeor types. When the hydrometeor is a sphere, it is assumed that it is either a hail stone or a small rain drop. When the hydrometeor is vertically orientated, it is typically an ice crystal, while when the hydrometeor is orientated horizontally, it indicates a medium to large rain drop. The $\rho_{H V}$ helps in the identification of the type of hydrometeor, and it suggests how similar hydrometeors are to each other (the hydrometeor type and its horizontal and vertical drop size distribution). For example, a $\rho_{H V}$ value close to 1 indicates a uniform drop size and shape distributions. Thus, $\rho_{H V}$ is useful for determining locations where different types of precipitation occur. The $K_{D P}$, which reduces the effect of radar signal attenuation in rainfall, indicates where the heaviest rainfall is likely occurring. Thereby, the $K_{D P}$ can help in predicting locations in storms where high precipitation intensities are expected to occur [53].

In addition, dual-pol radars offer other products as well, and their combinations can be used to determine precipitation intensities [53]. These combined products are less affected by attenuation and errors due to varying drop size distribution and, as a consequence, might lead to more accurate values of precipitation intensity.

Various precipitation estimators, most often in the form of $R\left(Z_{H}\right), R\left(Z_{H}, Z_{D R}\right), R\left(K_{D P}\right)$, and $R\left(K_{D P}, Z_{D R}\right)$, are proposed for dual-pol C-band and S-band weather radars [54-56]. Algorithms used for radar rainfall estimation are based on different combinations of the above-listed products. The comparison of QPE derived from dual-pol radar data with rain gauge accumulations by Montopoli et al. [54] indicates that a combined algorithm that merges different dual-pol parameters through a weight factor performs better in most cases than if a single radar product is used.

\subsubsection{Radar-Based Precipitation Estimates}

The quality-controlled 3D scan volumes measured by a weather radar are transformed by radar software into a set of specific two-dimensional (2D) products. For precipitation estimation, two products are mostly generated: precipitation intensity and precipitation accumulation. The surface precipitation intensity product is often derived as a cut-off at a constant height above ground level. Precipitation accumulation product is generated from two consecutive precipitation intensity products employing a spatial and temporal interpolation in order to avoid effects that are related to data sampling.

As mentioned above, radar measurements give very good spatial representation of precipitation but suffer from several sources of errors. In order to improve accuracy, the radar data are adjusted to rain gauge observations, which are assumed to provide more accurate point values $[57,58]$. The adjustment to rain gauge observations is used to reduce the systematic errors, such as differences in calibration, and, as a consequence, the underor overestimation. The bias adjustment factor is calculated from a comparison of total amounts of collocated radar and rain gauge precipitation values as a mean value for a given radar and for a given time step. The adjustment factor is usually determined from 
a comparison of a time sequence of radar estimates with corresponding rain gauge data, which are considered correct in the long term [59], in the order of a few hours at least.

The actual spatial variability of this adjustment factor results mainly from the increase in the height of the measurement with the distance from the radar site. Thus, this spatial variability can be taken into account by using the dependence of this factor on the distance from the radar site [57]. There are also more complex equations for the adjustment, which take into account more factors that affect the relationship between radar and rain gauge measurements [60]. The spatial adjustment factor retrieved by interpolation of gauge data to radar data is determined for each pixel of the precipitation field, and a ratio may be introduced in order to handle non-uniform bias within the radar composite domain.

\subsubsection{Machine Learning for Radar-Based Precipitation Estimates}

Rain gauge observations are frequently considered to be ground truth data; however, their reliability and spatial representation are limited. Gauge adjustment mostly depends on the rain gauge network distribution and real-time availability, which may be scarce and irregular, especially in complex terrain.

The use of machine learning techniques for quantitative precipitation estimation can be an alternative due to its simplicity. This approach aims at reducing the complexity of transforming reflectivity into rainfall, which usually accounts for several corrections and the upscaling of reflectivity before the application of a $Z-R$ equation. In contrast, machine learning-based QPE aims at mapping reflectivity into the precipitation intensity directly, i.e., without the intermediate steps. Several studies have used Artificial Neural Networks and decision tree-based techniques, such as Random Forests. Even though the techniques have some intrinsic disadvantages, e.g., the fact that neural networks are hard to tune, the results obtained using such methods are reported as promising [61,62].

\subsubsection{Weather Radar Composites}

Weather radar networks offer the possibility to cover a larger domain than a single instrument. In addition, networks allow for the improving of data quality of individual weather radars. As a result, it is possible to generate composites from the individual radar imagery. Generally, radar composites are known for better quality of data in the areas where radar scans overlap. Commonly, the compositing problem is understood as a question: how to merge the data from individual radars exploring the same area in order to preserve all reliable measurement information but removing or at least minimizing the influence of lower quality information?

The method, which is commonly used for producing radar composites in operational systems, attributes a maximum value to the pixel in the overlapping area. This compositing algorithm is usually applied due to its simplicity and ability to mitigate typical radar errors such as attenuation by heavy rain and beam blockage by terrain. However, the resulting composite product is not quality proofed and is usually overestimated [63,64]. It also propagates non-meteorological echoes from individual radars.

Thus, it is more appropriate to obtain the radar composite (i.e., precipitation field) by skilled merging of radar information characterized by spatially distributed uncertainties coming from individual radars. A skilled merging uses a criterion of highest quality or weighted average quality for selecting data from individual radars. Different quality factors can be applied for this purpose. Among these, the distance from the radar site or the height of the radar beam over the ground are widely used [64]. The general formula on the precipitation intensity $(R)$ is expressed as:

$$
R=\frac{\sum_{i=1}^{n} w_{i} \cdot R_{i}}{\sum_{i=1}^{n} w_{i}}
$$

where $R_{i}$ is the single radar reflectivity, $w_{i}$ is the weight of the $i-$ th radar, $i$ is the radar number, and $n$ is the number of radars covering a given pixel. 
The weights $w_{i}$ can be determined from a set of the abovementioned quality factors or by employing a single but more general quality metric (i.e., the quality index, $Q I$ ).

Figure 2 shows an example of the results of three radar data compositing methods, using the following criteria for merging: (i) the maximum value, (ii) the nearest radar value (minimum distance to the radar), and (iii) the value of the quality index. The maximum value method visually suggests a significant overestimation, while the nearest radar method shows clear boundaries between the individual radars. The QI-based method seems the most correct. The same conclusion can be derived from Figure 3, which compares values of RMSE using the three compositing methods. In Figure 3, the RMSE for the maximum value method shows a very large overestimation.

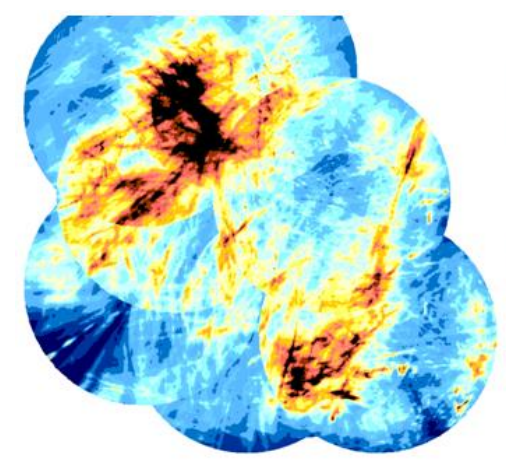

(a)

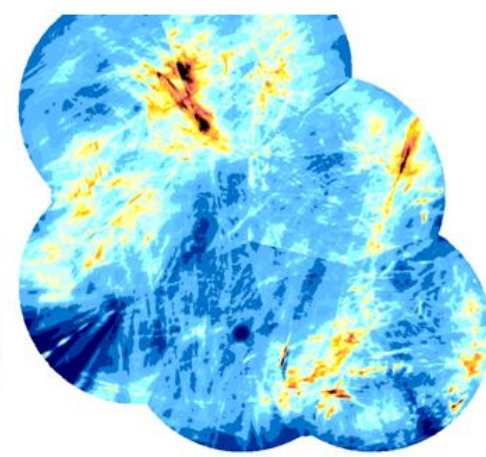

(b)

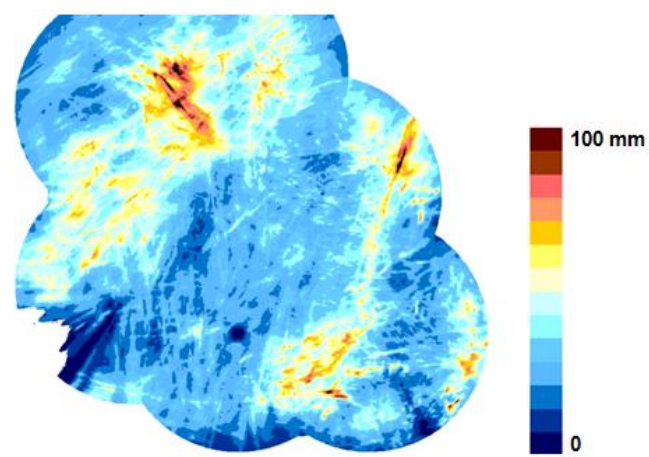

(c)

Figure 2. Precipitation fields aggregated for August 2017 resulting from weather radar compositing from 10-min accumulations using (a) the maximum value, (b) the value from the nearest radar, and (c) the quality index QI. Data from the POLRAD radar network consisting of eight radars are displayed (based on Jurczyk et al. [64]).

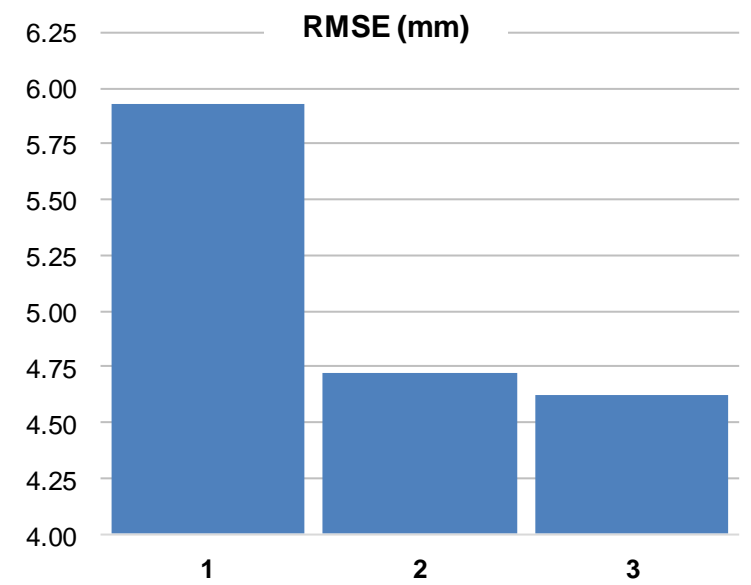

Figure 3. Comparison of daily accumulation of radar composites of POLRAD radar network with rain gauge accumulations in August 2017 in terms of RMSE using: 1-the maximum value, 2-the value from the nearest radar, and 3-the quality index QI (based on Jurczyk et al. [64]).

Usually, radar composite maps are created for networks of particular national meteorological services or at a trans-national scale. The two largest radar networks that generate radar composites are the American NEXRAD (Next Generation Weather Radar) and the European OPERA (Operational Program for Exchange of Weather Radar Information). The OPERA produces, inter alia, instantaneous surface precipitation intensities and hourly precipitation accumulations [50] based on data from more than 230 weather radars. 


\subsection{Multi-Source Precipitation Estimation}

Rain gauges supply accurate direct measurements at discrete points (i.e., point-wise) only; thus, the reproduction of their spatial distribution is limited by the density of the gauge network and errors associated with interpolation methods, which, in the case of a sparse gauge network, are hardly possible to perform. On the other hand, weather radar data provide us with trustworthy information about the spatial variability of rainfall with high spatial and temporal resolutions, though they are burdened with numerous errors of different structures that are too high to be neglected. The accuracy of satellite rainfall estimates remains questionable and the subject of ongoing worldwide research (see, e.g., Ebert et al. [65]). Nevertheless, satellites provide valuable information on the spatial distribution of rainfall, particularly for areas out of the weather radar range.

None of these precipitation estimating techniques seem to provide accurate precipitation estimation; however, they are largely complementary. Therefore, the idea of combining precipitation data from diverse sources emerged naturally in order to improve the accuracy of rainfall estimation. For instance, radar data have been combined with rain gauge data since the beginning of the operational use of weather radars in 1970s. Since that time, numerous merging methods have been developed to address the advantages and limitations of individual measurement techniques.

Several researchers have employed various deterministic methods for data merging based on gauge adjustment of radar observations by means of the computation of a constant multiplicative calibration factor, i.e., gauge-to-radar ratio, also known as a mean field bias (MFB). In range-dependent adjustment (RDA), it is assumed that the gaugeto-radar ratio is a function of the distance from the radar site. The RDA handles range related problems, such as the increasing height of the measurements, the beam broadening, and the attenuation effects. The static local bias correction aims at correcting visibility effects. It does not detect low precipitation accumulations at greater distances from the radar site. The static local bias is calculated from long-term data sets (e.g., one year) using a climatological gauge network [60]. A review of the methods based on gauge-to-radar ratio and their operational implementations in Europe can be found in the COST 717 report [57].

More sophisticated versions of the abovementioned techniques have also been investigated, e.g., the update of mean field bias between gauge and radar data in real time by Kalman filtering [66]. The more advanced statistical techniques developed for multisource precipitation estimation can be classified according to Velasco-Forero et al. [67] and Sideris et al. [29] as follows:

- $\quad$ statistical approaches based on multivariate analysis [68-70];

- radar-rain gauge probability distribution analysis based on the optimization of the $Z-R$ relationship using different matching techniques [71-73];

- $\quad$ geostatistical estimators, e.g., co-Kriging or Kriging with external drift [67,72,74-77];

- Bayesian methods (i.e., conditional merging) [78,79] including Kalman filtering [66,80-82].

These geostatistical and conditional methods generally consider a gauge as the primary source of data and radar as the secondary source of data.

Figure 4 shows a general example of combining gauge, radar, and satellite precipitation data obtained by a quality based conditional merging [25]. Spatially interpolated data from a relatively sparse rain gauge network differ quite significantly from radar estimates of the precipitation field, which are more heterogeneous. The satellite estimate is generally similar to the radar estimate, although it greatly varies in values and exact location of precipitation. The combined field of gauge, radar, and satellite precipitation data reflects the contribution of all the inputs, though the spatial distribution of precipitation is most similar to that of radar alone. 


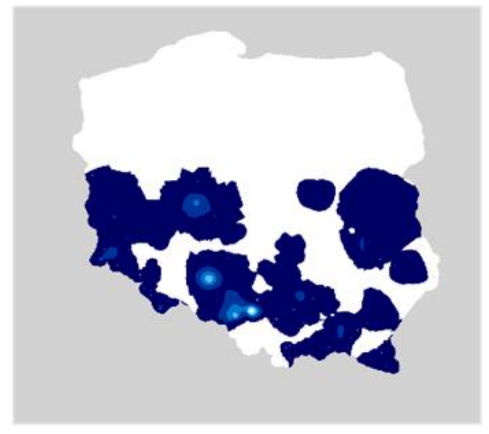

(a)

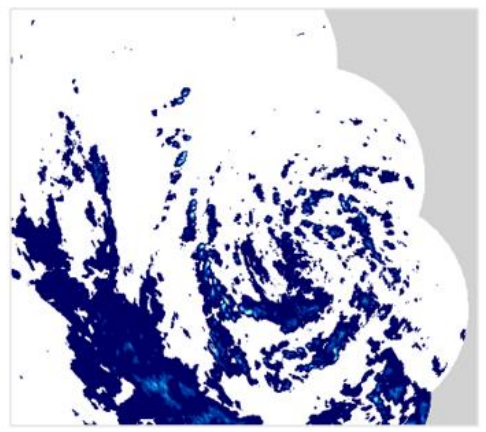

(b)

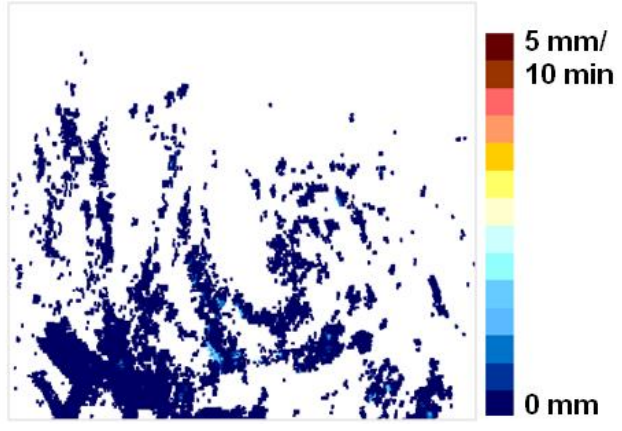

(c)

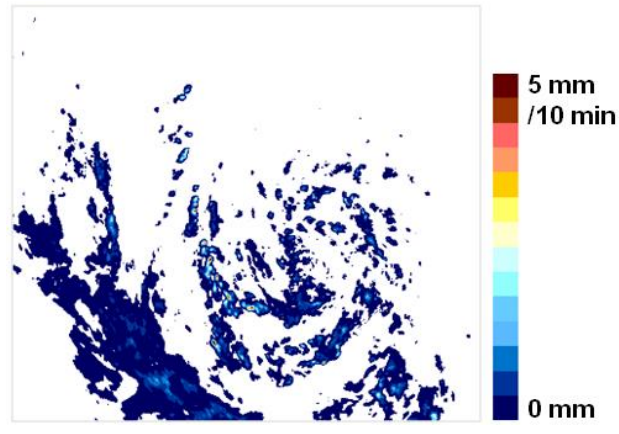

(d)

Figure 4. Precipitation fields (10-min. accumulations) in Poland, 22 May 2019, 14:20 UTC, RainGRS multi-source QPE model [25]. In the upper row from left to the right-results provided by (a) rain gauges, (b) weather radars, and (c) Meteosat satellite; at the bottom (d) combined precipitation field as a result of conditional merging (based on Jurczyk et al. [25]).

Numerous applications of these approaches have appeared in the literature, especially in hydrological modelling studies [79,83], climatological studies [84], and others. Most of these studies have provided valuable contributions to merging techniques. However, the usefulness of some methods for operational applications may be questionable, as they are very time-consuming.

Satellite precipitation estimates that are derived from visible and infrared channels from geostationary satellites or from microwave passive and active sensors (i.e., radars) onboard low near-polar satellites are merged with rain gauge observations less often. Chappell et al. [85] evaluated and selected geostatistical methods to merge satellite and gauge precipitation data analogous to those used for merging rain gauge and radar data.

The multi-source combination of gauge, radar, and satellite precipitation fields has also been proposed using, inter alia, the Bayesian approach [86], statistical objective analysis [69], and quality-based conditional merging [25]. These techniques are analogous to those applied to radar-rain gauge merging.

A comparison of results obtained using several different merging techniques can be found in, e.g., Goudenhoofdt and Delobbe [60] and McKee [83]. Figure 5 presents a comparison of radar-gauge combinations using the most commonly employed techniques. The results point out that simple methods like mean field bias correction can significantly reduce errors in the radar estimation. Nevertheless, there is a clear benefit in more sophisticated methods, the conditional merging (method 7) and Kriging with an external drift (method 8) being most effective. 


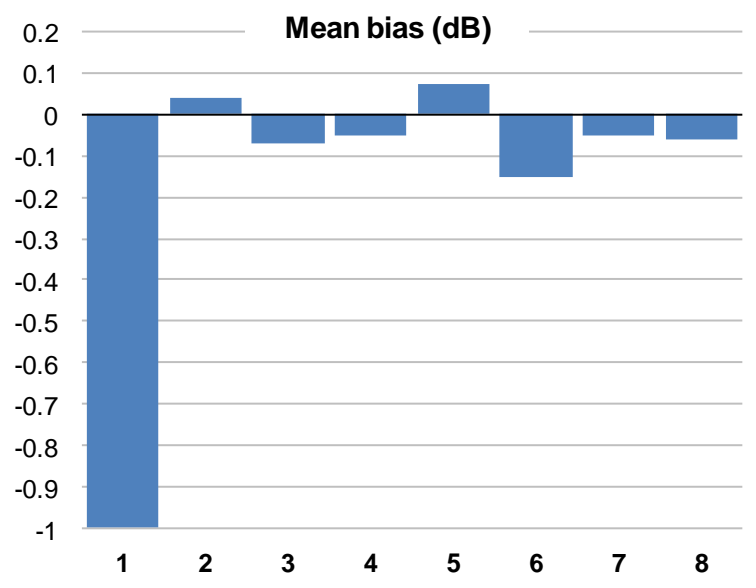

(a)

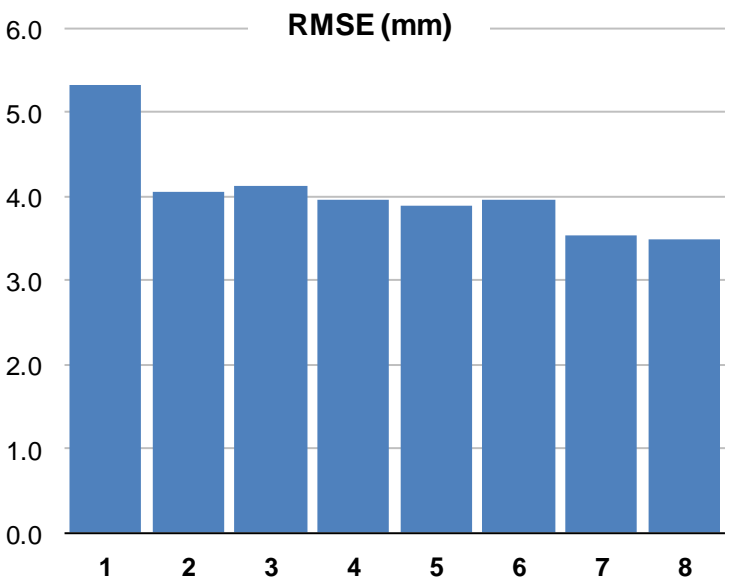

(b)

Figure 5. Mean bias (a) and root mean square error RMSE (b) of different radar-gauge merging methods based on four-year verification (2005-2008) in the gauge locations with gauge data as reference (adapted from Goudenhoofdt and Delobbe [60]). The investigated precipitation estimates are 1-radar-based precipitation, 2-radar-based precipitation after mean field bias correction, 3-radar-based precipitation after range-dependent adjustment, 4-radar-based precipitation after static local bias correction and range dependent adjustment, 5-radar-based precipitation after Brandes's [87] spatial adjustment, 6-rain gauge data interpolated using ordinary Kriging, 7-radar-gauge combination using Sinclair's and Pegram's technique [78], and 8-radar-gauge combination using Kriging with an external drift.

Analyzing the impact of the season on the effectiveness of combining different precipitation observations, Figure 6 shows that in winter, when widespread stratiform precipitation prevails, the spatial interpolation of a rain gauge network performs similarly to the multi-source data merging methods. However, in summer, when convective (and rather local) events occur, the added value of radar observations is evident $[25,60]$. It is worth noting that the merged product is only slightly better than the radar precipitation unbiased product using rain gauge data. Thus, a trade-off between computational time and accuracy improvement needs to be considered in real-time applications.

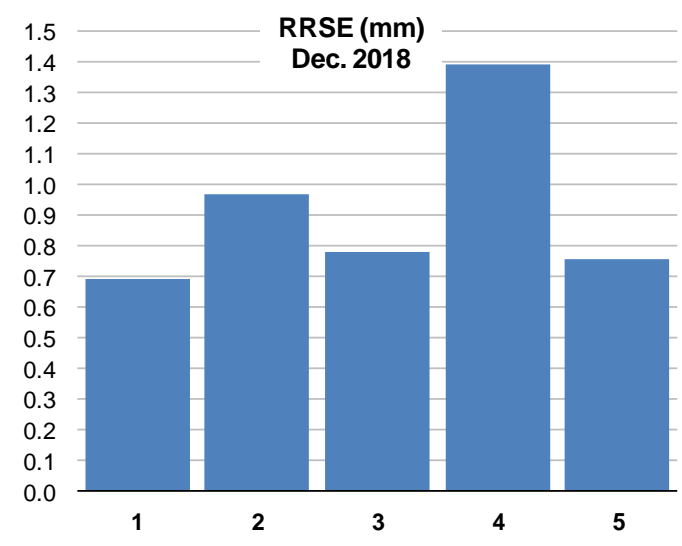

(a)

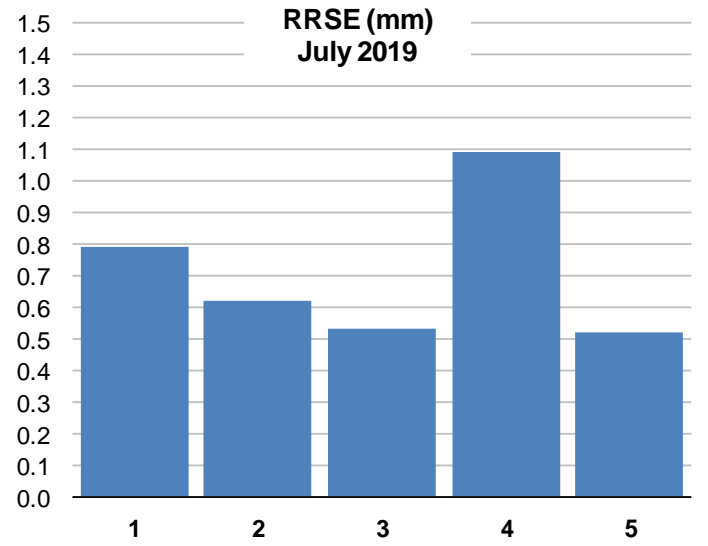

(b)

Figure 6. Monthly values of root relative squared error (RRSE) for precipitation fields using gauge data in the gauge locations as reference, obtained by: 1-interpolation of rain gauge data, 2-raw radar data, 3—unbiased radar data, 4—satellite data, and 5-conditional merging. The values are obtained for winter (December 2018; a) and summer (July 2019; b), based on Jurczyk et al. [25]. 


\section{Techniques for High-Resolution Nowcasting}

Heavy convective storms and torrential rains often cause flash floods, which can lead to significant economic damages and, in some cases, to losses of human life. Heavy rains evolve very quickly and affect limited areas; thus, they are very difficult to predict. Although general predictions determine well the suitable atmospheric conditions for severe storms, i.e., they are generally successful, we are currently not able to predict with a sufficient accuracy their precise location and time of occurrence and the specific (various) manifestations of individual storms (e.g., heavy rain, downburst, lightning) in order to substantially reduce consequential damages and/or losses. The main reason is that as the storms develop rapidly, they are identified by weather radars only a few tens of minutes before they manifest dangerously. In case of satellite data, spots of convection are identified a little earlier; however, it remains difficult to determine whether the convection will result in storm with dangerous impact or not.

Precipitation nowcasting employs four basic groups of methods. First group consists of extrapolation methods, which are based on current state of the atmosphere. The core of these extrapolation methods is the calculation of a motion vector and its extrapolation along Lagrangian trajectories. The extrapolation methods do not make use of forecasts provided by numerical weather prediction (NWP) models; instead, they do make use of radar data only. The second group of methods for precipitation nowcasting, called blending methods, combines extrapolation methods with forecasts by NWP models. The third group of methods for precipitation nowcasting comprises tools of artificial intelligence, such as neural networks. In contrast to the extrapolation methods, artificial intelligence-based models do not explicitly apply extrapolation along Lagrangian trajectories. The fourth group of methods for precipitation nowcasting forecasting is based on the application of conceptual models to simulate evolution.

Currently, there are a number of nowcasting systems that predict precipitation and other dangerous weather events and that are used operationally by meteorological services. In the following text, we focus on the description of basic principles of the nowcasting methods, which have been used, instead of on the description of nowcasting systems. Information about some of the nowcasting systems as well as their comparison can be found at web pages of individual national weather services. A detailed comparison of some of the systems has been done on the occasion of the Olympic games in Sydney [88] and Beijing [89].

\subsection{Extrapolation Methods}

Extrapolation methods represent the most widely used methods of precipitation nowcasting. A very frequently applied technique of extrapolation consists in the extrapolation of current radar-derived precipitation along Lagrangian trajectories. In this case, the basic data comprise radar reflectivities. Other sources of data describing precipitation processes in the atmosphere, such as satellite data or information on electric discharges in the atmosphere, can be used in extrapolation as well. Nevertheless, their use is not very frequent.

The main advantage of extrapolation methods is their low computational costs and fast calculation of forecasts. Another advantage is that they use currently measured data; therefore, the forecast is accurate for very short lead times, i.e., in the order of tens of minutes.

The main disadvantage of extrapolation methods lies in the fact that they do not model future development using physical properties of the atmosphere; instead, they are limited to a simple extrapolation of the current state with further development modelled using statistical models, if any.

In the following text, we describe how the motion field needed for extrapolation is obtained from the sequence of radar reflectivity measurements. After that, we characterize deterministic, probabilistic, and ensemble predictions of precipitation based on weather radar data. 


\subsubsection{Motion Field}

Diverse extrapolation methods have been developed differing in the calculation of the motion field and employed Lagrangian trajectories. The motion field is derived from the evolution of areal echoes of radar reflectivity measurements. At present, the most frequently used technique to derive motion fields is an optical flow method (OFM), which can be implemented using diverse algorithms [90-93]). The OFM method describes the flow using the advection equation only. It assumes that the analyzed radar images from different times change the values in the pixels by advection. Under this condition, optimal motion field between individual images is found.

Another technique deriving motion fields is the TREC (Tracking Radar Echo by Correlation) technique [94] or the COTREC (the Continuity of TREC) technique [95]. The difference between TREC and COTREC methods is that the later smooths the motion field, requiring that the continuity equation for horizontal wind components is met.

Both TREC and COTREC techniques solve the same problem as OFM, but by shifting the first radar image into different directions by varying distance and by comparing the match of the shifted image with the second one. The comparison is usually performed using correlations. The offset that shows the best match is selected as the motion vector.

For OFM, TREC, and COTREC, the motion vectors are determined locally in subareas. To increase the efficiency of both algorithms, it is necessary to have a good estimate of the motion field. In general, the OFM is being used more frequently for precipitation nowcasting than COTREC or TREC.

Once the motion field is known, Lagrangian trajectories can be calculated. Usually, the backward-in-time semi-Lagrangian method is applied for the calculation of trajectories, because it is quite robust with reasonable numerical diffusion and is easy to apply [91]. The practical advantage of the backward-in-time semi-Lagrangian method of calculation is evident when we aim at extrapolating precipitation to given grid points and given time. On the other hand, when we aim at forecasting the movement of individual storms, then forward-in-time technique is preferable.

Most extrapolation methods use a regular network of grid points, for which the motion field and precipitation forecasts are calculated. However, there are nowcasting methods, which monitor the development of individual storms using Storm Cell Identification and Tracking (SCIT) algorithms [96] or Thunderstorm Identification Tracking Analysis and Nowcasting (TITAN) [97]).

\subsubsection{Quantitative Precipitation Forecast}

The aim of quantitative precipitation forecasting is to predict the intensity of precipitation for a given place at a given time or to predict the sum of accumulated precipitation for a certain time interval for a given place or an area. Note that in this section, we consider deterministic forecasts only. Probabilistic and ensemble forecasts, which are more general, can also be used to get quantitative precipitation forecasts, and will be discussed in another subsection.

Extrapolation methods, discussed above, calculate the prediction for a given place and a given time by transferring the existing precipitation field along Lagrangian trajectories. Frequently, these methods assume that precipitation does not change over the time along the trajectories e.g., [91,98-104]. This assumption is acceptable in case of stratiform precipitation for forecasts with lead times of several hours; however, in case of convective precipitation, the precipitation can change (even significantly) along the trajectories. For example, Mejsnar et al. [105] showed that depending on the specific state of the atmosphere, the extrapolation should be applied for predictions of the order of minutes up to several tens of minutes only. Nevertheless, this prediction technique is often used for higher lead times, as it still provides useful information to forecasters in weather services.

The fact that simple extrapolation forecasts are inevitably inaccurate is taken into account by several prediction methods. These prediction methods assume that they cannot predict small scale features in precipitation fields such as storms affecting small areas 
and persisting for very short time. Therefore, these methods filter out gradually small scale features in time from the forecast, and they employ various stochastic models for this $[106,107]$. The Seed's approach [107] is called the Spectral Prognosis (S-PROG) model and uses Fourier filters to decompose rainfall fields into spectral scale components, and it forecasts each component independently. This approach is used in other methods as well [108].

The procedures filtering out the small-scale features of precipitation usually leads to a more accurate prediction if the prediction is verified using mean square error. Moreover, the actual improvement in the forecasts is also debatable, as it minimizes misplaced predictions for longer lead times by limiting the occurrence of precipitation to large objects only. Here, we would like to note that generally it is not possible to quantitatively describe the range of large objects or small features, since their dimensions may differ for different types of meteorological situations and depend on the resolution and quality of radar data.

\subsubsection{Probabilistic and Ensemble Forecasts}

There is a close relation between ensemble and probabilistic forecasts. A probabilistic forecast can be obtained from the ensemble prediction; however, the ensemble forecast is more general and can be used to evaluate possible economic losses related to inaccurate forecasts.

Probabilistic forecasts give a probability that an arbitrary threshold (e.g., precipitation threshold) is exceeded. The most straightforward technique providing probabilistic forecasts considers the forecasted values in the neighbourhood of a point of interest as possible forecasts. Then, using this dataset, the probabilistic forecast is calculated $[106,109]$. Another straightforward probabilistic technique was developed by Kitzmiller [110]. His technique is based on the application of regression models to extrapolated radar reflectivity data and selected NWP model variables [101,110]. Regression models are applied to describe relationships between yes/no predictand, i.e., the observed amount of precipitation that exceeded or did not exceed a threshold. In addition, the regression models consider predictors that are calculated either from forecasted (e.g., by NWP model) or observed meteorological variables. The most important and most used predictor is the precipitation derived from the latest radar measurement. A similar technique was applied by Pop et al. [111], who used two predictors and performed the Ensemble Tree Method to get the probability forecast of exceeding precipitation thresholds. Figure 7 depicts an example of a probabilistic forecast using an Ensemble Tree Model, as by Pop et al. [111], and a Linear Regression Model similar to that used by Kitzmiller [110] for a convective and a stratiform event that occurred in July 2012 in Czechia. The observed radar-derived precipitation field is hatched.

A probabilistic prediction can be also obtained from an ensemble prediction. The general idea of an ensemble prediction, which also applies extrapolation methods, is to take into account the uncertainty intrinsic to deterministic prediction. The core of an ensemble's prediction lies in the way the ensemble is generated. The generation of ensembles concentrates on quantities/characteristics that are burdened by greatest uncertainty. By modelling this uncertainty, it is then determined how it affects the overall prediction. Regarding the extrapolation, the basic uncertainty consists in the evolution of precipitation along the Lagrangian trajectories, which is not considered in the extrapolation. Therefore, the extrapolation methods are usually complemented by stochastic models, which model the development of precipitation along the Lagrangian trajectories. 


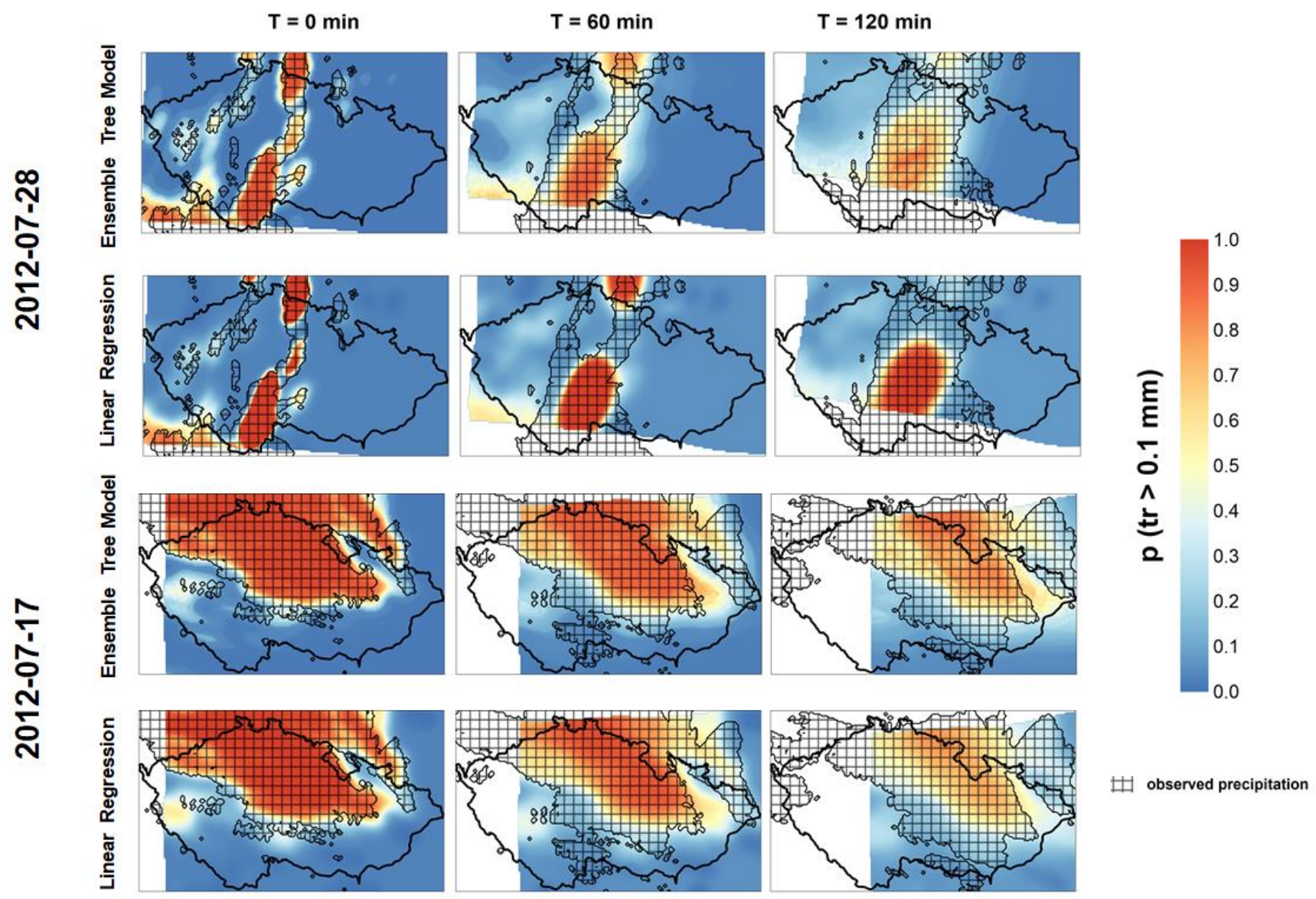

Figure 7. (adapted from Pop et al. [111]). Probabilistic forecast of exceeding a precipitation threshold $\mathrm{tr}=0.1 \mathrm{~mm}$ for a convective event on 28 July 2012 (first two rows) and a stratiform event on 17 July 2012 (third and fourth row) for a lead time $\mathrm{T}$ (from left to the right) of 0,60 , and $120 \mathrm{~min}$. The forecasted probability $\mathrm{p}(\mathrm{tr}>0.1 \mathrm{~mm})$ is depicted by color scale. Displayed forecasts represent results of an Ensemble Tree Model (first and third row) and a Linear Regression Model (second and fourth row). Note that the grey hatched area corresponds to observed precipitation field, derived from a C-band weather radar data.

Bowler et al. [112] proposed a stochastic precipitation nowcasting system (Short-Term Ensemble Prediction System; STEPS), which blended a spatially and temporally correlated cascade of noise fields with the radar extrapolation and NWP cascades. A similar approach was also applied by Atencia and Zawadzki [113], who developed a technique based on stochastic perturbation of a Lagrangian extrapolation of the last observed rainfall field using autoregressive models. They specifically designed the technique to reproduce the spatial and temporal structure of precipitation fields. In their work, Atencia and Zawadzki [113] found that the stochastic perturbations are able to reproduce the spatial structure of a precipitation field.

Berenguer et al. [114] developed an ensemble nowcasting technique called SBMcast by Lagrangian extrapolation. The core of the technique is to apply a String of Beads model [115] to generate ensemble members of precipitation forecasts. The utilized SBMcast model preserves the space and time structure of precipitation fields, thus making it compatible with observations. The results of Berenguer et al. [114] showed that the technique reasonably reproduces the evolution of rainfall fields, though the errors were underestimated. A possible reason for the underestimation of the errors was that the uncertainty errors related to motion field were neglected.

Another approach for precipitation nowcasting is the analogue-based approach, which finds similar states to the current state in a historical dataset. The main difficulty of this approach is, however, in finding the analogues. The ensemble is then created using several 
closest states to the historical data. For instance, Panziera et al. [116] developed a heuristic analogue technique called Nowcasting of Orographic Rainfall by means of Analogues (NORA) for a very short-term forecasting of orographic precipitation. In NORA, they used specific predictors that were selected as having strong relation with orographic precipitation and were characterizing the mesoscale conditions. The predictors were derived from radar images, and they were used to find the analogues. Foresti et al. [103] further improved this technique by using principal component analysis (PCA) to rainfall fields to find the analogues.

Atencia and Zawadzki [117] applied another approach to find analogues. They looked for similarities in temporal storm evolutions and synoptic patterns, and they concluded that the analogue-based probabilistic forecast has a better forecasting skill than the stochastic Lagrangian ensemble approach. Recently, also Pulkkinen et al. [118] published a method called Pysteps, which is an open-source Python library for probabilistic precipitation nowcasting and includes several above described techniques.

Sokol et al. [119] applied a completely different approach for an ensemble forecast. They used a two-step procedure for probabilistic forecasts of instantaneous precipitation. The basic idea of the method was first to model the uncertainty in the calculation of the trajectory using an ensemble, which is generated using historical data and the well-known LU (lower-upper) algorithm [120]) to derive the covariance structure of advection errors. In the second step, the error caused by neglecting the growth and decay of precipitation was estimated by applying the calibration with the aid of the decomposition of Brier Score and historical data.

\subsection{Blending Methods}

The idea of blending methods is to make optimal use of the advantages of the extrapolation method for forecasting and the prediction by NWP models. The (final) forecast is obtained by combination/weighting of the two forecasts, i.e., forecast by extrapolation and forecast by NWP model. Weights for the extrapolation forecasts are high for short lead times and decrease for higher lead times because of the inability of extrapolation methods to predict rainfall growth and decay. On the contrary, weights for NWP model forecasts increase with the increase of lead times. The weighting of forecasts is not trivial and is usually derived using historical data [121]). A well-known forecasting tool to the nowcasting of heavy precipitation is represented by the model NIMROD (Golding, 1998), which utilizes both the extrapolation of an existing precipitating field, which is derived from satellite and radar data, and precipitation forecasts of a NWP model. Another example of nowcasting system which includes precipitation nowcasting is Integrated Nowcasting Through Comprehensive Analysis INCA [100] (http:/ / www.inca-ce.eu/CE-Portal/).

It is interesting that various lead times (LT) can be found in literature for the case when a NWP model provided better forecasts of precipitation than the extrapolation technique [122]. For instance, Lin et al. [123] and Golding [124] found LT $=6 \mathrm{~h}$, Haiden et al. [100] obtained LT between 2 and $3 \mathrm{~h}$, and Bližňák et al. [104] found LT between 1 and $2 \mathrm{~h}$. It is important to note that one should consider the real availability of the NWP forecasts when using blending methods and that the differences in calculated LT might be related to different characteristics of given study regions.

\subsection{Artificial Intelligence-Based Methods}

Recently, a new nowcasting approach based on machine learning (ML) techniques has been also adopted, which highly differs from the above-mentioned standard methods. ML-based models can map certain inputs into a target variable (e.g., rainfall) without using physical equations that govern their relations and, to a large extent, also neglect the explicit statistical description of the problem.

Thus, ML-based models rely primarily on the data and their self-learning ability to construct the rules that allow converting the inputs into the expected output. MLalgorithms are used for this self-learning process by analyzing a large amount of historical 
data. Since most of ML-based models lack physical meaning, they are known as the so-called black box models.

In order to perform radar rainfall nowcasting, basically, the historical data of precipitation are used from in-situ observations and radar derivatives. Most of ML-based models have been implemented for predicting future rainfall images by using a video sequence as input for the model, which includes an internal representation of image evolution. This is, in fact, the core of standard extrapolating techniques, and thus it seems to be a promising approach and efficient way of nowcasting. However, it should be noted that building the inputs for the model requires to some extent implicit description of dynamic properties of the system.

One of applied techniques is the support vector machine (SVM). The SVM is a machine learning method based on statistical learning theory, which can solve non-linear and high dimensional classification problems with small sampling. For example, Mai et al. [125] used SVM as a classifier for categorical forecast of precipitation (yes/no). Other examples of the use of SVM for precipitation forecasting can be found in [126-128]. Besides SVM, other methods are also used for precipitation nowcasting, such as deep neural networks, convolutional neural networks, long short-term memory networks, etc. [129-131].

\subsection{Conceptual Models}

Conceptual models that describe the development of precipitation can be used for precipitation nowcasting as well. A well-known example of this approach is the automated nowcasting system of convective precipitation GANDOLF [132], which endeavors to simulate storm development. GANDOLF contains a conceptual model of the life cycle of convective clouds. With the help of satellite and radar data, and a variety of forecast products from a NWP model, GANDOLF identifies convective cells and predicts their possible development. Other examples of the application of conceptual models can be found in Roberts et al. [133] and Liu et al. [134], and it has been used in AutoNowCaster [135,136] (https://www.weather.gov/mdl/AutoNowCaster).

\section{Using Radar Data in NWP Modeling: Radar Data Assimilation}

The quality of prediction of precipitation by a NWP strongly depends on initial conditions (i.e., state of the atmosphere), which fundamentally influence the development of precipitation. In case of convective precipitation, the impact of initial conditions on forecast quality is even more significant due to high spatial and temporal variability of convective precipitation, as e.g., Ducrocq et al. [137] and Zhang et al. [138] have demonstrated. The aim of data assimilation into the NWP model is to determine the best possible initial conditions using observations and short range weather forecasts (https://www.ecmwf.int/en/research/data-assimilation). Data assimilation requires (i) a selection of data to be assimilated into a NWP model and (ii) a mathematical method of assimilation, which will create optimal initial conditions for the NWP model.

Data assimilation is a relatively complicated mathematical problem, and its thorough description would be too extensive for this paper and beyond the scope of it as well. Therefore, in this study, we deal with the mathematical part of the data assimilation marginally, and we focus more on ways the radar data can be used for data assimilation in order to refine the initial conditions for convection permitting NWP models.

Weather radars provide us with data, which contain important information about the ongoing state of the atmosphere as well as the development of convective cells. Research and its performed applications of over the last 30 years have convincingly shown that the radar data are very important for NWP models and their assimilation leads to substantial improvements in forecasting of convective events [139].

Weather radars usually give two kinds of information: (i) radar reflectivity and (ii) Doppler radial velocity. Assimilation of both kinds of radar data will be described in the two following sections. 


\subsection{Methods of Assimilation of Radar Reflectivity Data into a NWP}

Radar reflectivity data do not belong to basic model quantities of NWP models. Therefore, the immediately measured radar reflectivity data cannot be used in the assimilation directly. However, the radar reflectivity data can be derived from basic model quantities. Currently, there are three basic methods assimilating radar reflectivity data into NWP models.

\subsubsection{Latent Heat Nudging (LHN)}

Latent heat nudging (LHN) is a technique assimilating precipitation data into NWP models. This technique uses radar data, possibly in conjunction with other data related to precipitation, to estimate the observed precipitation. In locations where precipitation is observed, the NWP model temperature is artificially increased in the vertical profile. This approach stems from the knowledge that the majority of water vapor, which condenses in clouds, is precipitated out [140]. Therefore, the vertically integrated latent heating rate must be approximately proportional to the net precipitation rate due to the condensation in cloud.

However, this principle does not allow for any quantitative description of the temperature increase. In practice, it is possible to use the heating-profile lookup table, depending on the intensity of observed precipitation. The heating-profile lookup table can correspond to idealized temperature profiles, or they can be obtained from, e.g., statistically processed historical data of an NWP model. These temperature profiles are available at every grid point; however, they may not be appropriate for all the NWP models, because the change in a given temperature profile definitely depends on applied cloud microphysics in the model.

Therefore, LHN techniques nowadays employ latent heating profiles from the run of the applied NWP model, if it is available, and scale them using NWP model precipitation rate and the observed precipitation rate in the particular area. This is the general principle of LHN; however, in specific implementations, empirical parameters and procedures are used. Thus, individual implementations of LHN differ [141,142].

The accuracy of the forecast of convective storms and the associated precipitation significantly depend on the kind of convection and the specific situation. Therefore, the lead time for which the assimilation of radar reflectivity data has a positive effect on weather prediction significantly vary for individual cases and resolution of the model. In general, it can be stated that the LHN positively influences the forecast for lead times of about $6 \mathrm{~h}$. For instance, Jones and Macpherson [143] showed that their scheme provided a worthwhile increase in the skill of forecasting precipitation distribution in the first six to nine hours of the forecast. Similar results were obtained by Stephan et al. [142], who applied a revised LHN scheme in the COSMO NWP model. They showed that the model is able to simulate precipitation patterns in good agreement with radar observations during the assimilation and the first hours of the forecast, and they also proved a positive impact of assimilation using LHN on screen-level parameters and on the long-term climatology of the model.

\subsubsection{Water Vapor Correction Method}

A water vapor correction (WVC) method is very similar to the LHN method and to inverse modelling methods described below, but it uses a nudging technique instead of variational methods. WVC consists in adding or removing water vapor into or from the model's water vapor mixing ratio in a vertical profile. Supersaturation or subsaturation, which can follow corrections of water vapor, results in the release or absorption of heat, which invokes changes in the model temperature. The amount of added or removed water vapor, which is performed in a vertical profile, is based on the difference between forecasted precipitation and observed precipitation. However, quantitative expression of WVC stems from experiments.

WVC technique was applied by Falkovich et al. [144] for the first time. Sokol and Rezacova [145] modified the WVC technique and adapted it for precipitation nowcasting 
using a high resolution NWP model. Later, the WVC technique was even used for hail forecast [119] and was also combined with extrapolation nowcasting of radar reflectivity [146]. The results indicated that the WVC technique can improve precipitation nowcasting of severe convective storms for lead times of 2 to $3 \mathrm{~h}$.

\subsubsection{Inverse Modelling Technique}

The inverse modelling technique consists of using the actual result of some measurements to infer the values of the parameters that characterize the system. This procedure uses the so-called forward operator (FO), which calculates the measured quantity using the model variables.

Several mathematical techniques are currently used to find optimal to suboptimal initial conditions in case of radar data: (i) three dimensional variational assimilation (3DVar) [147], (ii) four dimensional variational assimilation (4DVar) [148,149], (iii) Ensemble Kalman Filter (EnKF) [150], and (iv) hybrid ensemble-variational method (EnVar) [151]. Both 3DVar and 4Dvar are variational methods. 4DVar considers time and performs optimization within time intervals, while 3DVar performs optimization at given time only. Moreover, 4DVar needs integrations of an adjoin model to make the optimization, which is time consuming; therefore, EnKF has been employed. Recently, EnVar has been developed, combining the best aspects of both the stand-alone ensemble-based method and standalone variational method. The main advantage of EnVar as compared to 4DVar is that EnVar does not use any adjoin model, which makes its implementation easier and significantly speeds up its performance.

The reason for using 4Dvar, EnKF, or EnVar instead of 3Dvar is that 3Dvar uses a static structure of the covariance error matrix, which is not realistic and negatively affects the quality of initial conditions and subsequent predictions of the NWP model [152-154]. Numerous studies have shown that the flow-dependent background error covariances, which are calculated and employed in 4Dvar, EnKF, and EnVar, provide better forecasts.

3Dvar was used for assimilation of radar reflectivity by Gao and Stensrud [155] and Gao and Min [153]. Recently, 4Dvar and EnKF are used more often. For instance, EnKF was used by Dowel et al. [156], Snook et al. [157], Yussouf and Stensrud [158], and Johnson et al. [152], while 4Dvar was used recently by Sun and Crook [159] and Caya et al. [160]. It should be mentioned that inverse modelling technique is frequently used for assimilating both the radar reflectivity and the Doppler radial velocities.

The relationship between the standard model quantities and radar reflectivity is not trivial. Therefore, different operators have been derived, which differ in their complexity and depend on considered processes and assumed simplifications. As a rule, attenuation of radar reflectivity is neglected in the operators, which is reasonable for data assimilated from a C-band or a S-band weather radars. However, in the case of data measured by $X$-band radars, the attenuation must be taken into account, either during measurement processing or in the FO. The former case was studied by Snook et al. [157] who applied a correction of the signal attenuation based on polarimetric differential phase [161].

Creating an FO can be avoided by converting the measured radar reflectivity data into "pseudo-observations" such as relative humidity or mixing ratio of hydrometeors, which are then assimilated into the model using one of the above described methods. Cloud water and ice are the hydrometeors that are often neglected in the assimilation, since they are considered to contribute only very little to the overall radar reflectivity [158]. The technique utilizing pseudo-observations is frequently used because of its simplicity (e.g., [158]). On the other hand, pseudo-observations can cause problems due to the strongly non-linear relationship between radar reflectivity and mixing ratio of different hydrometeors. This nonlinearity can, under certain conditions, disrupt the convergence of the variational method and, as a consequence, lead to a wrong determination of initial conditions for the NWP model [162]. Therefore, Wang and Wang [162] and later Duda et al. [163] suggested and applied a technique where the radar reflectivity was introduced as a state variable within the assimilation. 
The "pseudo-observations" approach is very similar to WVC described in Section 5.1.2; however, here the applied variational methods are more sophisticated and more accurate than the simple nudging applied in case of WVC.

It should be also noted that there are many publications describing experiments and drawing conclusions using pseudo-observations, including those referenced here, while publications assimilating observed data directly are less frequent [152,162].

\subsection{Assimilation of Doppler Radial Velocity into a NWP}

Assimilation of Doppler radial velocity is at least formally simpler than the assimilation of radar reflectivity data. The reason is that the components of air velocity are NWP model quantities and therefore, the derivation of a FO is simple. Thus, it is possible to apply the assimilation methods given in Section 5.1.3 on Doppler radial velocity data.

When formulating the FO, it is only necessary to consider the terminal velocity of hydrometeors, which affects the vertical component of measured velocity. Further, it is necessary to pay attention to the dealiasing of measured Doppler radial velocity. The measured Doppler radial velocity must be within an interval [-vmax, vmax], where vmax is the Nyquist velocity. Real radial velocities exceeding the interval [-vmax, vmax] are aliased. Thus, the dealiasing aims at determining actual (i.e., corrected) radial velocity. There are a number of methods solving the aliasing in the data, but most of them are based on comparison of measured radial velocities with velocities calculated from the field obtained by a NWP model prediction [164-166].

In the assimilation of radial velocity data, one can apply similar methods as those described in Section 5.1.3 for radar reflectivity data. Previously, 3Dvar and 4Dvar methods were used in the radial velocity assimilation $[152,154,155,159,160,167,168]$. Recently, EnKF and/or EnVar methods have prevailed [152,157,160,162,163,169-171].

Comparison of the results provided by individual methods does not give completely clear results. However, there is a consensus that the 3Dvar method gives the worst results. As for the radar reflectivity data, flow dependent background error covariance model is considered to provide better initial conditions and better forecasts when the radial velocity is assimilated $[152,154,159,168]$. Interesting results were shown by a recent paper [172] that studied assimilation using radar radial wind and reflectivity data in an idealized setup of the COSMO-KENDA system. The study showed that radial wind is more important to reconstruct dynamical structure of supercells, but if only radial winds are assimilated, a considerable amount of spurious convective cells is predicted. Thus, Zeng et al. [172] concluded that both the radial winds and the radar reflectivity are important for data assimilation, as they complement each other.

Comparison with other methods of data assimilation is usually case-based in literature. Thus, it is difficult to draw general conclusions. Further, diverse modifications and interconnections of various methods are used in addition to the basic assimilation approaches. While evaluating the assimilation methods, it is also necessary to consider the time complexity of individual methods, which is important from the operational point of view. We are therefore convinced that at present, it cannot be clearly stated which of the assimilation methods is the best or most appropriate.

\section{Using Radar Rainfall Data in Flash Flood Modeling}

The benefits of using rainfall radar data in hydrological applications were not reached effortlessly as one could have expected when this new spatially distributed data source became available [173]. Berne and Krajewski [174] discussed several aspects of the challenges of using weather radar in hydrological modelling while arguing that the evidence pointed to contradicting results regarding the improvements achieved by using radar-based rainfall data on rainfall-runoff distributed models. Whereas many studies reported an added value of the high resolution of radar rainfall data on hydrological applications, some others did not find a significant improvement. Currently, many more investigations have come to light and an updated overview of the use of radar rainfall on hydrology can 
be provided. Hereafter, the major radar-related topics on rainfall-runoff modelling and streamflow forecasting will be covered to highlight the main approaches and concerns that have been tackled in relation to the use of radar rainfall estimates. This section does not entail an intensive documentation of all studies in the field of radar hydrology, but rather a comprehensive review of the main topics that are discussed in the literature while providing some relevant examples. Therefore, it aims to provide a general outline of current investigations and challenges when dealing with radar data for hydrological applications with a focus on rainfall-runoff modelling, particularly flash-flood forecasting.

\subsection{Flash Flood Modelling Approaches Using Radar Data}

There are three different approaches for rainfall-runoff modelling, including flood forecasting, that have explored the usefulness of radar rainfall estimates. Those are processbased, machine learning-based, and data-based mechanistic models.

Process-based models can represent the hydrological processes with different degrees of detail, from small detail in lumped models (e.g., reservoir or tank models) to highly detailed, physically based, distributed models. When radar data became available, lumped models were preferred due to the low computational cost [175]. However, semi-distributed and distributed models have become more attractive due to the enormous increase in high computer power. Additionally, it is clear that the distributed nature of radar rainfall can be better exploited with a distributed model [176]. Nevertheless, distributed models are complex and have a large number of parameters that need to be calibrated in each model cell, which produces a large uncertainty in modelling estimates (i.e., the equifinality problem). Since all hydrological processes are represented in detail, distributed models demand large amounts of distributed data sets: vegetation, topography, soils, land use, and geology, to name a few. These data are seldom available at the scale of interest, which limits the applicability of these models.

Another source of uncertainty comes from the selection of the initial conditions, mainly the soil moisture conditions (SMC). To account for correct SMC, the model needs to include a detailed soil map, the soils' hydrological properties, and also distributed soil depths. Since soils and their properties are highly variable in mountain catchments, and very difficult and expensive to collect, the application of distributed models in mountain environments faces a big challenge. The problem of SMC initialization in the model is more complex for flash flood forecasting than for general rainfall-runoff modelling (as for hydrological design or post-event analyses), as the model needs to have good initial conditions for obtaining good results. Thus, each time the forecast is initialized (every few hours), the forecasting system has to update its SMC, which can be highly demanding and subject to uncertainty [177], although soil moisture assimilation strategies have proved successful in distributed models [178]. Using distributed models remains challenging, although they can benefit more from radar data. On the other hand, lumped models are used when there is scarce spatially-distributed data and/or computer power is limited. In this case, radar rainfall is aggregated at the basin scale (e.g., area-weighted mean of the overlaying radar grid cells), losing the details of the rainfall fields. This can be slightly avoided when applied in small catchments. Therefore, semi-distributed models are considered as a compromise between lumped and distributed models, where it is still possible to capture some details of the spatial variability while maintaining accessible data requirements. Here, the basin is divided into subbasins, and in each of them a lumped model is used [179]. While there are difficulties in the application of distributed models, there are modelling objectives that can only be answered with them: hydrological impact of land use changes or discharge forecasting in rapidly evolving catchments [180].

With the advent of artificial intelligence, the use of models based on machine learning (ML) models for rainfall-runoff mapping and discharge forecasting has dramatically increased. These models are known for their outstanding performance, but also for their complex training process and for being considered as black box models. Thus, model parameters lack physical interpretation regarding the runoff processes. A comprehensive 
review of several ML algorithms used for flood forecasting using radar rainfall data is provided by Mosavi et al. [181]. Besides the use of support vector machines, the authors highlighted the use of a variety of Artificial Neural Networks (ANN) derived models, such as neuro-fuzzy, adaptive neuro-fuzzy inference systems (ANFIS), wavelet neural networks $(\mathrm{WNN})$, and multilayer perceptron (MLP), as the more frequent models in the literature. More sophisticated ML-based models such as genetic programming [182] have also been explored with satisfactory results. Nonetheless, other ML-based models as those based on decision trees (DT) are less complex algorithms that have just recently been explored by using radar rainfall [183]. Even though many ML algorithms serve as black box models, deep learning (DL) approaches have been demonstrated that are able to provide some insights about the relations of the inputs that fed the model towards the discharge. It should be of great advantage and interest to extract some knowledge of the rainfall-runoff process by using these techniques as a reverse engineering strategy. Kratzert et al. [184] performed a study using Long Short Term Memory (LSTM) ANN over 241 catchments and showed the ability of this DL approach to learn long-term dependencies between the inputs and the output of the model (e.g., those related to modelling storage effects) along with the possibility to transfer process understanding from the regional to the local scale. Recently, Xiang and Demir [185] proposed the use of DL for extending the forecast horizon until five days on an hourly basis with promising results. Because there is a very recent interest on the application of DL for discharge forecasting, it has been tested by using only spatially distributed rainfall derived from dense rain gauges. Therefore, the benefits of applying DL on radar rainfall for streamflow forecasting remain unknown.

Finally, data base mechanistic (DBM) models are another type of hydrological model that combines a statistical definition of the rainfall-runoff model with a supervised optimization of its parameters that ensures that the model parameters have a physical meaning. DBM models have been less explored for rainfall-runoff modelling, but have also proven to be efficient when using radar rainfall forecasts in small mountain catchments [186]. In DBM models, radar data is aggregated as in a lumped model; thus, the distributed rainfall fields are lost. On the whole, there is a major need for research on developing smart model structures that are able to properly incorporate, as far as possible, the distributed nature of radar rainfall data. Thus, taking advantage of radar data comes from a combined strategy as a result of expert knowledge and the individual strengths of a hydrological model.

\subsection{Uncertainty in Radar Estimates for Hydrological Modeling}

Although radar-based precipitations estimates are known to provide significant spatially distributed rainfall information, they are still subject to errors, which can notoriously reduce hydrological model performances [187]. Radar rainfall estimation is a necessary step for the use of spatially distributed rainfall on physically-based hydrological models. Thus, as weather radar provides an indirect measurement of rainfall (i.e., reflectivity), the transformation from reflectivity to rainfall implies many processes that add uncertainty to the estimations. Despite the nature of ML-based models that would allow the mapping of any input (independently of its physical meaning or interpretation) to an output, the vast majority of studies that applied ML-based models for streamflow modelling or forecasting also performed a radar rainfall retrieval process as a previous step to the modelling itself in order to guarantee a proper quantitative representation of rainfall [183].

Quantification of uncertainty of radar estimates is of main importance, particularly when using physically-based models. It is because the quantitative estimation of the radar rainfall retrievals strongly influences model results. Studies with physically-based models have focused on two main sources of uncertainty: uncertainty in rainfall input [188-190] originated from the systematic errors produced in the process of $Z-R$ transformation, and uncertainty in model parameters [191,192]. Investigations on radar hydrology are more frequently focused on rainfall input uncertainty.

In a trade-off between the added error of the radar rainfall derivation chain and the improvement on the radar rainfall estimates, the bias adjustment by means of rain gauge 
networks has been extensively accepted for applications on radar hydrology, while efforts have been made to reduce the negative effects of relative calibration on radar composites, as in Seo et al. [193]. For instance, uncertainty in radar rainfall estimates was evaluated by Seo et al. [188] using different radar rainfall products that differ on the data composition (i.e., only radar-based product vs. rain gauge bias-adjusted radar product). The study demonstrated the need for bias-adjusted radar estimates related to the Iowa Flood Studies (IFloodS) experiment. Nonetheless, according to Paz et al. [194], the heterogeneous distributions of rain gauge networks for radar bias adjustment strongly affect the quality of adjusted rainfall fields because of the fractality of the rain gauge network.

One strategy for evaluating the uncertainty of rainfall estimates is to use ensemble models. Here, some changes in the configuration of the model (input source, model parameters, or both) are carried out, and the corresponding model evaluation is performed, as in Pomeón et al. [192]. A radar rainfall ensemble is the result of the application of an error model, which may account for observed errors (i.e., as compared with rain gauges), spatial and temporal dependences, and their marginal distribution, that reflects several possible realizations on the rainfall field $[189,190]$. Thus, through the application of a hydrological model by using different radar rainfall ensembles, it is possible to evaluate the radar input uncertainty. Error models range from simple schemes that add a fixed Gaussian random error and evaluate the radar rainfall ensembles on different hydrological models [195] to more refined but also complex error models that include geostatistical approaches for the generation of synthetic error fields [189] and non-Gaussian distributions [190].

Another approach that has been explored for quantifying the precipitation data uncertainty when using spatial distributed rainfall is a Bayesian analysis that accounts for influence of the length of the rainfall time series. For instance, Sikorska and Seibert [196] evaluated different rainfall data sources: only gauge station, interpolated gauge station, and radar-based precipitation in an alpine catchment by using different time series lengths for the model calibration process. The authors found the radar-based precipitation was more informative for the model, which derived in the higher accuracy. Thus, the evaluation of ensemble models towards several realizations of probability distributions allow uncertainty bands to be obtained, which exhibits the robustness of the model under induced errors on the input radar data. Therefore, this is a powerful tool not only for researchers, but also mainly for decision-makers using flood forecasting, which needs to be transferred to early-warning operational systems.

Even though the measurement error of weather radar retrievals cannot be avoided, the systematic error that comes from the $Z-R$ transformation could be disregarded when using raw reflectivity records as inputs for ML-based models. Very recently, OrellanaAlvear et al. [183] demonstrated the suitability of using the native radar variable (reflectivity) as input for a random forest model for discharge forecasting. Performance of the model was comparable with the use of radar rainfall estimates, and therefore the authors concluded that differences should be overlooked. It opened a new alternative for performing discharge forecasting by using native radar data, which is extremely beneficial in regions with sparse and uneven distributed rain gauge networks, that would reduce the uncertainty of systematic errors.

\subsection{Radar Spatial Resolution and Catchment Scale}

The added value of a finer spatial resolution of radar imagery for hydrological models is usually taken for granted. Thus, many studies have been conducted with the objective to identify the best radar spatial resolution for hydrological applications (e.g., Shakti et al. [197]). Results suggested that higher rainfall resolutions are relevant at smaller catchment scales and mainly when rainfall events of high variability occur. For instance, Thorndahl et al. [18], in their review, identified a reduced need of high resolution radar rainfall for bigger urban catchments. As illustration, a comparison of the use of C-band and X-band radar data as rainfall inputs for rainfall-runoff models was performed by Paz et al. [198] in an urbanized catchment $\left(3 \mathrm{~km}^{2}\right)$ close to Paris. Results pointed to a 
better representation of X-band radar rainfall with a spatial resolution of $250 \times 250 \mathrm{~m}^{2}$ at $3.41 \mathrm{~min}$ frequency in contrast to the $1 \times 1 \mathrm{~km}^{2}$ spatial resolution of the C-band radar data at $5 \mathrm{~min}$ frequency. Evaluation on a small $\left(64 \mathrm{~km}^{2}\right)$ mountainous catchment in the Italian Alps confirmed the benefits on X-band spatial resolution data for peak simulation [199]. A review paper of the effects of spatial and temporal variability on hydrological response in urban areas was performed by Cristiano et al. [200]. The authors concluded from the literature that physically-based models have become more specialized, and high-resolution spatial rainfall data is of utmost need to take advantage of the models.

Furthermore, Cristiano et al. [201] introduced dimensionless scaling factors that reflect the interactions between rainfall, its input resolution, and catchment on the hydrological response in urban areas. The novelty of these scaling factors is that they allow the identification of the needed rainfall resolution in order to reach a given level of accuracy in model performance. Most studies (e.g., Anagnostou et al. [199]; Paz et al. [198]) in the literature have performed an evaluation of the impact of the radar rainfall resolution (i.e., spatial and temporal) in the hydrological response over a specific catchment, which impedes the generalization of their results. In this context, it is still difficult to assess if the findings in these studies respond to the size of the catchment, the variability of the rainfall event in time and space, the particularities of the terrain, etc. Nonetheless, those that have been able to reproduce their analysis on a wider scope have concluded that sensitivity of the hydrological models to different rainfall resolutions decreased when the size of the catchment increased. For instance, Ochoa-Rodriguez et al. [17] performed an analysis of the impact of different rainfall spatial $(100-3000 \mathrm{~m})$ and temporal $(1-10 \mathrm{~min})$ resolutions at seven urban catchments that differ on the geomorphological characteristics of their locations by using $\mathrm{X}$-band polarimetric radar data. The authors found that a temporal resolution lower than $5 \mathrm{~min}$ is needed for performing an adequate hydrological modelling, whereas a spatial resolution of $3 \mathrm{~km}$ (cartesian grid size) does not properly work for urban catchments.

Another relevant study that provided streamflow simulation evaluation by using a quite diverse dataset of 3620 flood events that occurred over 181 catchments of a variety of sizes and climate conditions was carried out by Lobligeois et al. [202]. Rather than focusing on the evaluation of a combination of spatial and temporal resolutions or radar data, this study used radar-based data with a fixed $1 \mathrm{~km}, 1-\mathrm{h}$ resolution over a 10-year period in France as input for a lumped and a distributed model. Results were analyzed by considering catchment location and types of rainfall events (i.e., spatial variability of rainfall). The authors found that both models, lumped and distributed, performed similarly on the catchments in western France that are under oceanic climate conditions and thus exhibit fairly uniform precipitation fields. In contrast, the spatially distributed rainfall data was greatly beneficial to the model accuracy in southern France, where mountain catchments with highly variable precipitation in space are located. Interestingly, in certain regions, distributed models can outperform simpler models in certain periods of the year (e.g., when rainfall fields are complex), while in other periods they do not; thus, Loritz et. al. [176] propose the development of adaptive models as a way to exploit the information of distributed rainfall while reducing the computational costs of modelling.

All in all, studies suggest that the combination of catchment biophysical characteristics (e.g., land use, topography, soils), rainfall types (orographic, convective, stratiform), rainfall variability in time and space, and modelling objectives (flash flood forecasting, hydrologic design) determine the required radar spatio-temporal resolution and model complexity.

\subsection{Usefulness of Blending Data and Ancillary Data}

With the aim of improving the accuracy of rainfall-runoff modelling and discharge forecasting, ancillary data that relates to the physical runoff processes are usually included. Regularly, semi-distributed and distributed models already need additional geomorphological variables for an adequate model calibration. Nonetheless, additional information that comes from rainfall forecasts, NWP, and more sophisticated blending techniques of rainfall data have proven to enhance the performance of rainfall-runoff models and 
discharge forecasting by allowing the extension of the forecast horizon while using different modelling strategies. Ochoa-Rodriguez et al. [203] provided an in-depth review of radar-rain gauge merging techniques by proposing an application-oriented categorization. This classification accounted for radar bias adjustment methods, geostatistical methods such as kriging techniques, and finally integration methods where neither radar nor rain gauge data are considered as a primary data source, but a combination of both that extracts the best information from each instrument is produced as a final result. From those, mean field bias adjustment, kriging with external drift, and Bayesian merging were found the most relevant techniques. These methods were reviewed by considering their use in urban hydrology applications, and therefore they are a good starting point for evaluating their effectiveness on rainfall-runoff modelling. Likewise, McKee and Binns [204] performed a similar review but with a focus on near real-time application of gauge radar merging methods in operational systems. Moreover, the inclusion of satellite-based soil moisture estimations [177] or a related representation (e.g., a proxy based on rainfall accumulation) in addition to the radar-based rainfall information, has satisfactorily improved runoff modelling and discharge forecasting with distributed models [205].

Besides the blending of radar-rain gauge data, the inclusion of short-term radar rainfall forecasts is an important strategy that has improved streamflow forecasting. For instance, Heuvelink et al. [206] demonstrated that the use of radar rainfall nowcasting improves the hydrological response, but also comes with the highest uncertainty in smaller catchments. It was an expected result, since rainfall forecasts were found to diminish its accuracy with increasing lead time. This effect also responded to other studies previously mentioned where smaller catchments are usually associated with higher spatial variability of rainfall. Heuvelink et al. [206] found that the best scenario of discharge forecasting showed a gain of almost three hours more in advance than without rainfall nowcasting.

Finally, the use of Numerical Weather Predictions (NWP) as inputs for rainfall-runoff modelling has gained much attention on the last years. Radar rainfall data can be used for assimilation, thus forcing the generation of NWP, which would enhance its accuracy. As NWP provide longer-term rainfall forecast, its use as input for discharge forecasting has allowed not only the improvement the model performance, but also the increase of the lead time forecasts. More sophisticated techniques may involve blending data dynamically with changing weight functions. For instance, the combination of NWP and radar-based predictions with corrections for orographic rainfall whose weights are computed according to their expected skills can be found in Yu et al. [207]. A relevant illustration of three operational early warning systems for flash flood forecasting in Europe that showed the advantage of using a combination of different data sources is documented in Alfieri et al. [208].

\subsection{Post-Event Flash Flood Analyses}

Radar data has been extensively used in studies of flash flood processes understanding. Since heavy rainfall events-particularly in mountain areas-cannot be captured by conventional rain gauge networks, radar data opened a whole new dimension to the study of flash floods. Post-event analyses (e.g., Bouilloud et al. [209]; Marchi et al. [210]) or forensic hydrological (e.g., Bronstert et al. [211]; Borga et al. [212]) are studies that reconstruct (flash) floods in an attempt to understand the triggering mechanisms and the development of these extreme events; this new knowledge is then later used for developing forecasting models. Under this scheme, forecast models can be improved or developed further as to effectively simulate the flash flood processes given the detailed precipitation input, but hydrological models can also serve as test beds to identify adjustments to radar rainfall data (Borga et al. [213]; Seo et al. [193]). As an example, Javelle et al. [214] analyzed the forecasting performance of a distributed model for different lead times in absence of quantitative precipitation forecasting. Radar data was able to improve simulations for short lead times; main limitations were attributed to both rainfall underestimation and the modelling uncertainty. 
In summary, studying the combination of meteorological aspects, rainfall fields, hydrological processes, hydrological modelling, and human activities (e.g., land use change in floodplains) allows for an in-depth comprehension of flood events [211]. This knowledge-together with social and infrastructure data-is crucial for flash flood risk management [215]. Here, radar data has been key to understanding the impact of spatial distribution of rainfall and its evolution along the event.

\section{Conclusions}

Weather radar measurements have enormous potential in hydrological applications, though they are still not fully utilized. The main direction of current research is the effective use of their high temporal and spatial resolution-it is assumed that the desired resolution for small catchments, in particular the urbanized ones, should be up to $1 \mathrm{~km}$ (cartesian grid size) and up to $5 \mathrm{~min}$ in space and time, respectively, and weather radar is the only device that can provide such a high resolution.

However, the biggest limitation of the use of weather radar data for hydrological applications is in their quality. More and more effective quality control algorithms are being developed thanks to more advanced image processing techniques related to increasing computing possibilities, including those based on machine learning. At the same time, however, there are new challenges, such as those resulting from the increasing presence of RLAN signals particularly disrupting weather radars operating in the most popular C-band and those resulting from the negative impact of wind farms on radar measurements. The radar errors are hard to diagnose and thus hard to remove completely. Thereby, data from other measuring systems, rain gauge networks in particular, are used to improve the radar-based quantitative precipitation estimation through either its adjustment or the multi-source combination.

New perspectives appear with the increasingly better availability of weather radar data from on board meteorological satellites in low Earth orbits, since such radars have a completely different error structure than the common ground-based weather radars. Moreover, crowdsourcing measurements become more and more popular, especially those from private meteorological stations, as the data from private meteorological stations can be a valuable supplement to national rain gauge networks and can be used for adjustment of weather radar data or generation of multi-source estimates.

Methods for precipitation nowcasting for early warning against dangerous precipitation are commonly used by meteorological services. These methods use current data and process it using statistical methods and/or artificial intelligence methods, thus avoiding the high time consumption of complex mathematical models used for medium-term weather forecasts. The nowcasting models are computationally undemanding and do not require large data sets. They usually give reasonable predictions for lead times up to $2 \mathrm{~h}$ with a high frequency of calculations (e.g., every $10 \mathrm{~min}$ ). The basic limitation of the nowcasting methods is their limited accuracy for longer lead times, i.e., after a certain time, the nowcasting methods can no longer compete with standard NWP models. The accuracy of nowcasts depends strongly on the type of meteorological situation. For instance, in the case of severe convection, nowcasting can give a reasonable forecast for 10 to $20 \mathrm{~min}$ only.

Various nowcasting procedures can be used, which differ in the kind of prediction: (i) quantitative, (ii) categorical, (iii) probabilistic, and (iv) ensemble. Each kind of prediction has its own advantages and disadvantages, but there is a clear tendency of considering the uncertainty of methods in the development of methods, which leads to a preference of ensemble or probabilistic prediction. Nevertheless, every user of a nowcasting method should be aware that the parameters are determined subjectively, i.e., they are not of general validity. Therefore, each nowcasting model should be tuned specifically for the area of interest, and its properties should be considered if the model outputs are further used, e.g., in hydrological applications. All in all, despite fundamental shortcomings, the nowcasting models are currently irreplaceable. 
Assimilation of data into NWP models is an important way to refine forecasts. Radar data are very important for the forecast, as they contain detailed and spatially dense information on hydrometeors in the atmosphere. It is obvious that both types of radar data, i.e., radar reflectivity and Doppler radial velocity, are important for prediction of cloud development and precipitation; however, it is not entirely clear whether the Doppler radial velocity or the radar reflectivity is more important for assimilation. Recent studies have suggested that assimilation of a particular type of data refines the prediction of only certain processes. Therefore, it can be recommended to assimilate both types of radar data, which appears to have complementary effect.

Several assimilation methods for radar data assimilation differ for radar reflectivity and Doppler radial velocity. The difference is mainly due to the fact that the Doppler radial velocity is a model quantity, while the reflectivity is a derived variable from model quantities. The general tendency in data assimilation is the use of sophisticated methods, which include features of the $4 \mathrm{D}$ variation method, but also the use of simplifications that allow fast enough assimilation of the data. In parallel to these methods, techniques based on the application of an ensemble Kalman filter are used and developed. Nevertheless, applications of the nudging technique in conjunction with the assimilation of radar reflectivity, such as latent heat nudging, have still occasionally appeared in literature, since they are very efficient in terms of computational demands.

The use of radar rainfall data for flash flood modelling needs to be further exploited by strategies that combine expert knowledge and the specific advantages and strengths of different hydrological models. This would allow the development of smart model structures that leverage the spatially distributed nature of radar data. Nonetheless, radar imagery has proven to be already a key component to improve the understanding of flash flood events and their development when used as reverse engineering. This knowledge is of utmost importance for risk management related to the reduction of social and infrastructure impacts of flash flood events.

Author Contributions: Conceptualization: Z.S., J.S., J.O.-A., A.J. and R.C.; writing—original draft: Z.S., J.S., J.O.-A., J.P., A.J. and R.C.; visualization-J.S. and J.P.; writing-review and editing: Z.S., J.O.-A., J.P. and R.C. All authors have read and agreed to the published version of the manuscript.

Funding: The participation of Z.S. and J.P. was funded by project CRREAT (reg. number: CZ.02.1.01/0.0/ 0.0/15_003/0000481) call number 02_15_003 of the Operational Programme Research, Development, and Education and was also supported by Charles University (UNCE/HUM 018) and by project Strategy AV21, Water for Life. The participation of J.O.-A. and R.C. was funded by the project "Highresolution radar analysis of precipitation extremes in Ecuador and North Peru and implications of the ENSO-dynamics", a collaborating project from the German Research Foundation (Deutsche Forschungsgemeinschaft-DFG; DFG GZ.: RO3815/2-1) and the Research Office of the University of Cuenca (DIUC). The research was partially funded by the Technology Agency of the Czech Republic (grant no. SS02030040, PERUN).

Institutional Review Board Statement: Not applicable.

Informed Consent Statement: Not applicable.

Conflicts of Interest: The authors declare no conflict of interest. The funders had no role in the design of the study; in the collection, analyses, or interpretation of data; in the writing of the manuscript; or in the decision to publish the results.

\section{References}

1. Marshall, J.S.; Langille, R.C.; Palmer, W.M.K. Measurement of Rainfall by Radar. J. Meteor. 1947, 4, 186-192. [CrossRef]

2. Wilk, K.E.; Kessler, E. Quantitative Radar Measurements of Precipitation. In Meteorological Observations and Instrumentation; Teweles, S., Giraytys, J., Eds.; American Meteorological Society: Boston, MA, USA, 1970; pp. 315-329, ISBN 978-1-935704-35-5.

3. Wilson, J.W.; Brandes, E.A. Radar Measurement of Rainfall-A Summary. Bull. Amer. Meteor. Soc. 1979, 60, 1048-1060. [CrossRef]

4. Zawadzki, I. Factors Affecting the Precision of Radar Measurements of Rain. In Proceedings of the 22nd Conference on Radar Meteorology, Boston, MA, USA, 1 January 1984; pp. 251-256. 
5. Joss, J.; Waldvogel, A.; Collier, C.G. Precipitation Measurement and Hydrology. In Radar in Meteorology: Battan Memorial and 40th Anniversary Radar Meteorology Conference; Atlas, D., Ed.; American Meteorological Society: Boston, MA, USA, 1990; pp. 577-606, ISBN 978-1-935704-15-7.

6. Krajewski, W.F.; Smith, J.A. Radar Hydrology: Rainfall Estimation. Adv. Water Resour. 2002, 25, 1387-1394. [CrossRef]

7. Collier, C.G. Applications of Weather Radar Systems: A Guide to Uses of Radar Data in Meteorology and Hydrology, 2nd ed.; John Wiley \& Sons: Chichester, UK; New York, NY, USA, 1996; ISBN 978-0-471-96013-3.

8. Zappa, M.; Beven, K.J.; Bruen, M.; Cofiño, A.S.; Kok, K.; Martin, E.; Nurmi, P.; Orfila, B.; Roulin, E.; Schröter, K.; et al. Propagation of Uncertainty from Observing Systems and NWP into Hydrological Models: COST-731 Working Group 2. Atmos. Sci. Lett. 2010, 11, 83-91. [CrossRef]

9. Zhang, Y.; Xie, S.; Klein, S.A.; Marchand, R.; Kollias, P.; Clothiaux, E.E.; Lin, W.; Johnson, K.; Swales, D.; Bodas-Salcedo, A.; et al The ARM cloud radar simulator for global climate models: Bridging field data and climate models. Bull. Am. Meteorol. Soc. 2018, 99, 21-26. [CrossRef]

10. Joss, J. Operational Use of Radar for Precipitation Measurements in Switzerland; Vdf Hochschulverl. an der ETH Zürich: Zürich, Switherlands, 1998; ISBN 978-3-7281-2501-9.

11. Savina, M.; Schäppi, B.; Molnar, P.; Burlando, P.; Sevruk, B. Comparison of a Tipping-Bucket and Electronic Weighing Precipitation Gage for Snowfall. Atmos. Res. 2012, 103, 45-51. [CrossRef]

12. Gires, A.; Tchiguirinskaia, I.; Schertzer, D.; Schellart, A.; Berne, A.; Lovejoy, S. Influence of Small Scale Rainfall Variability on Standard Comparison Tools between Radar and Rain Gauge Data. Atmos. Res. 2014, 138, 125-138. [CrossRef]

13. Song, Y.; Han, D.; Rico-Ramirez, M.A. High Temporal Resolution Rainfall Information Retrieval from Tipping-Bucket Rain Gauge Measurements. Procedia Eng. 2016, 154, 1193-1200. [CrossRef]

14. De Vos, L.; Leijnse, H.; Overeem, A.; Uijlenhoet, R. The Potential of Urban Rainfall Monitoring with Crowdsourced Automatic Weather Stations in Amsterdam. Hydrol. Earth Syst. Sci. 2017, 21, 765-777. [CrossRef]

15. Berne, A.; Delrieu, G.; Creutin, J.; Obled, C. Temporal and Spatial Resolution of Rainfall Measurements Required for Urban Hydrology. J. Hydrol. 2004, 299, 166-179. [CrossRef]

16. Emmanuel, I.; Andrieu, H.; Leblois, E.; Flahaut, B. Temporal and Spatial Variability of Rainfall at the Urban Hydrological Scale. J. Hydrol. 2012, 430-431, 162-172. [CrossRef]

17. Ochoa-Rodriguez, S.; Wang, L.-P.; Gires, A.; Pina, R.D.; Reinoso-Rondinel, R.; Bruni, G.; Ichiba, A.; Gaitan, S.; Cristiano, E.; van Assel, J.; et al. Impact of Spatial and Temporal Resolution of Rainfall Inputs on Urban Hydrodynamic Modelling Outputs: A Multi-Catchment Investigation. J. Hydrol. 2015, 531, 389-407. [CrossRef]

18. Thorndahl, S.; Einfalt, T.; Willems, P.; Nielsen, J.E.; ten Veldhuis, M.-C.; Arnbjerg-Nielsen, K.; Rasmussen, M.R.; Molnar, P. Weather Radar Rainfall Data in Urban Hydrology. Hydrol. Earth Syst. Sci. 2017, 21, 1359-1380. [CrossRef]

19. Yoon, J.; Joo, J.; Yoo, C.; Hwang, S.; Lim, S. On Quality of Radar Rainfall with Respect to Temporal and Spatial Resolution for Application to Urban Areas. Meteorol. Appl. 2017, 24, 19-30. [CrossRef]

20. Michaelides, S.; Levizzani, V.; Anagnostou, E.; Bauer, P.; Kasparis, T.; Lane, J.E. Precipitation: Measurement, Remote Sensing, Climatology and Modeling. Atmos. Res. 2009, 94, 512-533. [CrossRef]

21. Michelson, D.B. Systematic Correction of Precipitation Gauge Observations Using Analyzed Meteorological Variables. J. Hydrol. 2004, 290, 161-177. [CrossRef]

22. Martinaitis, S.M.; Cocks, S.B.; Qi, Y.; Kaney, B.T.; Zhang, J.; Howard, K. Understanding Winter Precipitation Impacts on Automated Gauge Observations within a Real-Time System. J. Hydrometeor. 2015, 16, 2345-2363. [CrossRef]

23. WMO. Guide to the Global Observing System, 3rd ed.; World Meteorological Organization: Geneva, Switherlands, 2007.

24. Otop, I.; Szturc, J.; Ośródka, K.; Djaków, P. Automatic Quality Control of Telemetric Rain Gauge Data for Operational Applications at IMGW-PIB. ITM Web Conf. 2018, 23, 00028. [CrossRef]

25. Jurczyk, A.; Szturc, J.; Otop, I.; Ośródka, K.; Struzik, P. Quality-Based Combination of Multi-Source Precipitation Data. Remote Sens. 2020, 12, 1709. [CrossRef]

26. Ahrens, B. Distance in Spatial Interpolation of Daily Rain Gauge Data. Hydrol. Earth Syst. Sci. 2006, 10, 197-208. [CrossRef]

27. Han, D.; Bray, M. Automated Thiessen Polygon Generation. Water Resour. Res. 2006, 42. [CrossRef]

28. Berndt, C.; Rabiei, E.; Haberlandt, U. Geostatistical Merging of Rain Gauge and Radar Data for High Temporal Resolutions and Various Station Density Scenarios. J. Hydrol. 2014, 508, 88-101. [CrossRef]

29. Sideris, I.V.; Gabella, M.; Erdin, R.; Germann, U. Real-Time Radar-Rain-Gauge Merging Using Spatio-Temporal Co-Kriging with External Drift in the Alpine Terrain of Switzerland. Q. J. R. Meteorol. Soc. 2014, 140, 1097-1111. [CrossRef]

30. Orellana-Alvear, J.; Célleri, R.; Rollenbeck, R.; Bendix, J. Analysis of Rain Types and Their Z-R Relationships at Different Locations in the High Andes of Southern Ecuador. J. Appl. Meteor. Clim. 2017, 56, 3065-3080. [CrossRef]

31. Neuper, M.; Ehret, U. Quantitative Precipitation Estimation with Weather Radar Using a Data- and Information-Based Approach. Hydrol. Earth Syst. Sci. 2019, 23, 3711-3733. [CrossRef]

32. Meischner, P. (Ed.) Weather Radar: Principles and Advanced Applications; Physics of Earth and Space Environments; Springer: Berlin/Heidelberg, Germany, 2004; ISBN 978-3-540-00328-1.

33. Michelson, D.B.; Einfalt, T.; Holleman, I.; Gjertsen, U.; Friedrich, K.; Haase, G.; Lindskog, M.; Jurczyk, A. COST Action 717: Weather Radar Data Quality in Europe-Quality Control and Characterization: Review; EUR-OP: Luxembourg, 2005; ISBN 92-898-0018-6. 
34. Villarini, G.; Krajewski, W.F. Review of the Different Sources of Uncertainty in Single Polarization Radar-Based Estimates of Rainfall. Surv. Geophys. 2010, 31, 107-129. [CrossRef]

35. Ośródka, K.; Szturc, J.; Jurczyk, A. Chain of Data Quality Algorithms for 3-D Single-Polarization Radar Reflectivity (RADVOL-QC System). Meteorol. Appl. 2014, 21, 256-270. [CrossRef]

36. Gekat, F.; Meischner, P.; Friedrich, K.; Hagen, M.; Koistinen, J.; Michelson, D.B.; Huuskonen, A. The State of Weather Radar Operations, Networks and Products. In Weather Radar: Principles and Advanced Applications; Springer: Berlin/Heidelberg, Germany, 2004; pp. 1-51.

37. Krajewski, W.F.; Vignal, B.; Seo, B.-C.; Villarini, G. Statistical Model of the Range-Dependent Error in Radar-Rainfall Estimates Due to the Vertical Profile of Reflectivity. J. Hydrol. 2011, 402, 306-316. [CrossRef]

38. Sebastianelli, S.; Russo, F.; Napolitano, F.; Baldini, L. On Precipitation Measurements Collected by a Weather Radar and a Rain Gauge Network. Nat. Hazards Earth Syst. Sci. 2013, 13, 605-623. [CrossRef]

39. Angulo, I.; Grande, O.; Jenn, D.; Guerra, D.; de la Vega, D. Estimating Reflectivity Values from Wind Turbines for Analyzing the Potential Impact on Weather Radar Services. Atmos. Meas. Tech. 2015, 8, 2183-2193. [CrossRef]

40. Norin, L. A Quantitative Analysis of the Impact of Wind Turbines on Operational Doppler Weather Radar Data. Atmos. Meas. Tech. 2015, 8, 593-609. [CrossRef]

41. Seo, B.-C.; Krajewski, W.F.; Mishra, K.V. Using the New Dual-Polarimetric Capability of WSR-88D to Eliminate Anomalous Propagation and Wind Turbine Effects in Radar-Rainfall. Atmos. Res. 2015, 153, 296-309. [CrossRef]

42. Saltikoff, E.; Cho, J.Y.N.; Tristant, P.; Huuskonen, A.; Allmon, L.; Cook, R.; Becker, E.; Joe, P. The Threat to Weather Radars by Wireless Technology. Am. Meteorol. Soc. 2016, 97, 1159-1167. [CrossRef]

43. Gauthreaux, S.; Diehl, R. Discrimination of Biological Scatterers in Polarimetric Weather Radar Data: Opportunities and Challenges. Remote Sens. 2020, 12, 545. [CrossRef]

44. Bech, J.; Gjertsen, U.; Haase, G. Modelling Weather Radar Beam Propagation and Topographical Blockage at Northern High Latitudes. Q. J. R. Meteorol. Soc. 2007, 133, 1191-1204. [CrossRef]

45. McRoberts, D.B.; Nielsen-Gammon, J.W. Detecting Beam Blockage in Radar-Based Precipitation Estimates. J. Atmos. Ocean. Technol. 2017, 34, 1407-1422. [CrossRef]

46. Gu, J.-Y.; Ryzhkov, A.; Zhang, P.; Neilley, P.; Knight, M.; Wolf, B.; Lee, D.-I. Polarimetric Attenuation Correction in Heavy Rain at C Band. J. Appl. Meteor. Clim. 2011, 50, 39-58. [CrossRef]

47. Bebbington, D.; Rae, S.; Bech, J.; Codina, B.; Picanyol, M. Modelling of Weather Radar Echoes from Anomalous Propagation Using a Hybrid Parabolic Equation Method and NWP Model Data. Nat. Hazards Earth Syst. Sci. 2007, 7, 391-398. [CrossRef]

48. Lee, H.; Kim, S. Ensemble Classification for Anomalous Propagation Echo Detection with Clustering-Based Subset-Selection Method. Atmosphere 2017, 8, 11. [CrossRef]

49. Einfalt, T.; Szturc, J.; Ośródka, K. The Quality Index for Radar Precipitation Data: A Tower of Babel? Atmos. Sci. Lett. 2010, 11, 139-144. [CrossRef]

50. Huuskonen, A.; Saltikoff, E.; Holleman, I. The Operational Weather Radar Network in Europe. Bull. Am. Meteor. Soc. 2014, 95, 897-907. [CrossRef]

51. Saltikoff, E.; Haase, G.; Delobbe, L.; Gaussiat, N.; Martet, M.; Idziorek, D.; Leijnse, H.; Novák, P.; Lukach, M.; Stephan, K. OPERA the Radar Project. Atmosphere 2019, 10, 320. [CrossRef]

52. Michelson, D.; Henja, A.; Ernes, S.; Haase, G.; Koistinen, J.; Ośródka, K.; Peltonen, T.; Szewczykowski, M.; Szturc, J. BALTRAD Advanced Weather Radar Networking. J. Open Res. Softw. 2018, 6, 12. [CrossRef]

53. Bringi, V.N.; Chandrasekar, V. Polarimetric Doppler Weather Radar: Principles and Applications; Cambridge University Press: Cambridge, UK, 2001; ISBN 978-0-521-62384-1.

54. Montopoli, M.; Roberto, N.; Adirosi, E.; Gorgucci, E.; Baldini, L. Investigation of Weather Radar Quantitative Precipitation Estimation Methodologies in Complex Orography. Atmosphere 2017, 8, 34. [CrossRef]

55. Simpson, M.J.; Fox, N.I. Dual-Polarized Quantitative Precipitation Estimation as a Function of Range. Hydrol. Earth Syst. Sci. 2018, 22, 3375-3389. [CrossRef]

56. Voormansik, T.; Cremonini, R.; Post, P.; Moisseev, D. Use of Dual-Polarization Weather Radar Quantitative Precipitation Estimation for Climatology. Hydrol. Earth Syst. Sci. Discuss. 2020, 1-14. [CrossRef]

57. Gjertsen, U.; Šálek, M.; Michelson, D.B. COST Action 717: Use of Radar Observation in Hydrological and NWP Models: GaugeAdjustement of Radar-Based Precipitation Estimates: Review; COST Action 717; EUR-OP: Luxembourg, 2004; ISBN 978-92-898-0000-6.

58. Bruen, M.; O'Loughlin, F. Towards a Nonlinear Radar-Gauge Adjustment of Radar via a Piece-Wise Method. Meteorol. Appl. 2014, 21, 675-683. [CrossRef]

59. Berg, P.; Norin, L.; Olsson, J. Creation of a High Resolution Precipitation Data Set by Merging Gridded Gauge Data and Radar Observations for Sweden. J. Hydrol. 2016, 541, 6-13. [CrossRef]

60. Goudenhoofdt, E.; Delobbe, L. Evaluation of Radar-Gauge Merging Methods for Quantitative Precipitation Estimates. Hydrol. Earth Syst. Sci. 2009, 13, 195-203. [CrossRef]

61. Alqudah, A.; Chandrasekar, V.; Le, M. Investigating Rainfall Estimation from Radar Measurements Using Neural Networks. Nat. Hazards Earth Syst. Sci. 2013, 13, 535-544. [CrossRef]

62. Orellana-Alvear, J.; Célleri, R.; Rollenbeck, R.; Bendix, J. Optimization of X-Band Radar Rainfall Retrieval in the Southern Andes of Ecuador Using a Random Forest Model. Remote Sens. 2019, 11, 1632. [CrossRef] 
63. Fornasiero, A.; Alberoni, P.P.; Amorati, R.; Marsigli, C. Improving the Radar Data Mosaicking Procedure by Means of a Quality Descriptor. In Proceedings of the ERAD, Barcelona, Spain, 18-22 September 2006; pp. 378-381.

64. Jurczyk, A.; Szturc, J.; Ośródka, K. Quality-Based Compositing of Weather Radar Derived Precipitation. Meteorol. Appl. 2020, 27, e1812. [CrossRef]

65. Ebert, E.E.; Janowiak, J.E.; Kidd, C. Comparison of Near-Real-Time Precipitation Estimates from Satellite Observations and Numerical Models. Bull. Amer. Meteor. Soc. 2007, 88, 47-64. [CrossRef]

66. Chumchean, S.; Seed, A.; Sharma, A. Correcting of Real-Time Radar Rainfall Bias Using a Kalman Filtering Approach. J. Hydrol. 2006, 317, 123-137. [CrossRef]

67. Velasco-Forero, C.A.; Sempere-Torres, D.; Cassiraga, E.F.; Jaime Gómez-Hernández, J. A Non-Parametric Automatic Blending Methodology to Estimate Rainfall Fields from Rain Gauge and Radar Data. Adv. Water Resour. 2009, 32, 986-1002. [CrossRef]

68. Pereira Filho, A.J.; Crawford, K.C.; Hartzell, C.L. Improving WSR-88D Hourly Rainfall Estimates. Weather Forecast. 1998, 13, 1016-1028. [CrossRef]

69. Pereira Filho, A.J. Integrating Gauge, Radar and Satellite Rainfall. In Proceedings of the 2nd International Precipitation Working Group Workshop, Monterey, CA, USA, 25-28 October 2004.

70. Šálek, M.; Novák, P.; Seo, D.-J. Operational Application of Combined Radar and Raingauges Precipitation Estimation at the CHMI. In Proceedings of the ERAD, Copernicus GmbH, Visby, Island of Gotland, Sweden, 6-10 September 2004; pp. 16-20.

71. Rosenfeld, D.; Wolff, D.B.; Amitai, E. The Window Probability Matching Method for Rainfall Measurements with Radar. J. Appl. Meteor. 1994, 33, 682-693. [CrossRef]

72. Sun, X.; Mein, R.G.; Keenan, T.D.; Elliott, J.F. Flood Estimation Using Radar and Raingauge Data. J. Hydrol. 2000, 239, 4-18. [CrossRef]

73. Piman, T.; Babel, M.S.; Das Gupta, A.; Weesakul, S. Development of a Window Correlation Matching Method for Improved Radar Rainfall Estimation. Hydrol. Earth Syst. Sci. 2007, 11, 1361-1372. [CrossRef]

74. Krajewski, W.F. Cokriging Radar-Rainfall and Rain Gage Data. J. Geophys. Res. Atmos. 1987, 92, 9571-9580. [CrossRef]

75. Seo, D.-J. Real-Time Estimation of Rainfall Fields Using Radar Rainfall and Rain Gage Data. J. Hydrol. 1998, 208, 37-52. [CrossRef]

76. Haberlandt, U. Geostatistical Interpolation of Hourly Precipitation from Rain Gauges and Radar for a Large-Scale Extreme Rainfall Event. J. Hydrol. 2007, 332, 144-157. [CrossRef]

77. Delrieu, G.; Wijbrans, A.; Boudevillain, B.; Faure, D.; Bonnifait, L.; Kirstetter, P.-E. Geostatistical Radar-Raingauge Merging: A Novel Method for the Quantification of Rain Estimation Accuracy. Adv. Water Resour. 2014, 71, 110-124. [CrossRef]

78. Sinclair, S.; Pegram, G. Combining Radar and Rain Gauge Rainfall Estimates Using Conditional Merging. Atmos. Sci. Lett. 2005, 6, 19-22. [CrossRef]

79. Ehret, U.; Götzinger, J.; Bárdossy, A.; Pegram, G.G.S. Radar-based Flood Forecasting in Small Catchments, Exemplified by the Goldersbach Catchment, Germany. Int. J. River Basin Manag. 2008, 6, 323-329. [CrossRef]

80. Todini, E. A Bayesian Technique for Conditioning Radar Precipitation Estimates to Rain-Gauge Measurements. Hydrol. Earth Syst. Sci. 2001, 5, 187-199. [CrossRef]

81. Seo, D.-J.; Breidenbach, J.P. Real-Time Correction of Spatially Nonuniform Bias in Radar Rainfall Data Using Rain Gauge Measurements. J. Hydrometeor. 2002, 3, 93-111. [CrossRef]

82. Sivasubramaniam, K.; Sharma, A.; Alfredsen, K. Merging Radar and Gauge Information within a Dynamical Model Combination Framework for Precipitation Estimation in Cold Climates. Environ. Model. Softw. 2019, 119, 99-110. [CrossRef]

83. McKee, J. Evaluation of Gauge-Radar Merging Methods for Quantitative Precipitation Estimation in Hydrology: A Case Study in the Upper Thames River Basin. Electronic Thesis, University of Western Ontario, London, UK, 2015; p. 151.

84. Saltikoff, E.; Friedrich, K.; Soderholm, J.; Lengfeld, K.; Nelson, B.; Becker, A.; Hollmann, R.; Urban, B.; Heistermann, M.; Tassone, C. An Overview of Using Weather Radar for Climatological Studies: Successes, Challenges, and Potential. Bull. Am. Meteor. Soc. 2019, 100, 1739-1752. [CrossRef]

85. Chappell, A.; Renzullo, L.J.; Raupach, T.H.; Haylock, M. Evaluating Geostatistical Methods of Blending Satellite and Gauge Data to Estimate near Real-Time Daily Rainfall for Australia. J. Hydrol. 2013, 493, 105-114. [CrossRef]

86. Todini, E.; Mazzetti, C. A Bayesian Multisensor Combination Approach to Rainfall Estimate. In Proceedings of the 2nd International Symposium on Communications, Control and Signal Processing, Marrakech, Morocco, 13-15 March 2006 ; p. 5.

87. Brandes, E.A. Optimizing Rainfall Estimates with the Aid of Radar. J. Appl. Meteor. 1975, 14, 1339-1345. [CrossRef]

88. Pierce, C.E.; Ebert, E.; Seed, A.W.; Sleigh, M.; Collier, C.G.; Fox, N.I.; Donaldson, N.; Wilson, J.W.; Roberts, R.; Mueller, C.K. The Nowcasting of Precipitation during Sydney 2000: An Appraisal of the QPF Algorithms. Weather Forecast. 2004, 19, 7-21. [CrossRef]

89. Wilson, J.W.; Feng, Y.; Chen, M.; Roberts, R.D. Nowcasting Challenges during the Beijing Olympics: Successes, Failures, and Implications for Future Nowcasting Systems. Weather Forecast. 2010, 25, 1691-1714. [CrossRef]

90. Lucas, B.D.; Kanade, T. An Iterative Image Registration Technique with an Application to Stereo Vision. In Proceedings of the 7th international joint conference on Artificial intelligence, San Francisco, CA, USA, 24 August 1981; Morgan Kaufmann Publishers Inc.: San Francisco, CA, USA, 1981; Volume 2, pp. 674-679.

91. Germann, U.; Zawadzki, I. Scale-Dependence of the Predictability of Precipitation from Continental Radar Images. Part I: Description of the Methodology. Mon. Weather Rev. 2002, 130, 2859-2873. [CrossRef] 
92. Bouguet, J.-Y. Pyramidal Implementation of the Lucas Kanade Feature Tracker. Intel Corporation, Microprocessor Research Labs. 2000. Available online: http:/ / robots.stanford.edu/cs223b04/algo_tracking.pdf (accessed on 20 January 2021).

93. Ruzanski, E.; Chandrasekar, V.; Wang, Y. The CASA Nowcasting System. J. Atmos. Ocean. Technol. 2011, 28, 640-655. [CrossRef]

94. Rinehart, R.E.; Garvey, E.T. Three-Dimensional Storm Motion Detection by Conventional Weather Radar. Nature 1978, 273, 287-289. [CrossRef]

95. Li, L.; Schmid, W.; Joss, J. Nowcasting of Motion and Growth of Precipitation with Radar over a Complex Orography. J. Appl. Meteor. 1995, 34, 1286-1300. [CrossRef]

96. Johnson, J.T.; MacKeen, P.L.; Witt, A.; Mitchell, E.D.W.; Stumpf, G.J.; Eilts, M.D.; Thomas, K.W. The Storm Cell Identification and Tracking Algorithm: An Enhanced WSR-88D Algorithm. Weather Forecast. 1998, 13, 263-276. [CrossRef]

97. Dixon, M.; Wiener, G. TITAN: Thunderstorm Identification, Tracking, Analysis, and Nowcasting-A Radar-Based Methodology. J. Atmos. Ocean. Technol. 1993, 10, 785-797. [CrossRef]

98. Novák, P. The Czech Hydrometeorological Institute's Severe Storm Nowcasting System. Atmos. Res. 2007, 83, 450-457. [CrossRef]

99. Reyniers, M. Quantitative Precipitation Forecasts Based on Radar Observations: Principles, Algorithms and Operational Systems; Institut Royal Météorologique de Belgique: Brussel, Belgium, 2008.

100. Haiden, T.; Kann, A.; Wittmann, C.; Pistotnik, G.; Bica, B.; Gruber, C. The Integrated Nowcasting through Comprehensive Analysis (INCA) System and Its Validation over the Eastern Alpine Region. Weather Forecast. 2011, 26, 166-183. [CrossRef]

101. Sokol, Z.; Pesice, P. Nowcasting of Precipitation-Advective Statistical Forecast Model (SAM) for the Czech Republic. Atmos. Res. 2012, 103, 70-79. [CrossRef]

102. Sokol, Z.; Zacharov, P. Nowcasting of Precipitation by an NWP Model Using Assimilation of Extrapolated Radar Reflectivity. Q. J. R. Meteorol. Soc. 2012, 138, 1072-1082. [CrossRef]

103. Foresti, L.; Panziera, L.; Mandapaka, P.V.; Germann, U.; Seed, A. Retrieval of Analogue Radar Images for Ensemble Nowcasting of Orographic Rainfall. Meteorol. Appl. 2015, 22, 141-155. [CrossRef]

104. Bližňák, V.; Sokol, Z.; Zacharov, P. Nowcasting of Deep Convective Clouds and Heavy Precipitation: Comparison Study between NWP Model Simulation and Extrapolation. Atmos. Res. 2017, 184, 24-34. [CrossRef]

105. Mejsnar, J.; Sokol, Z.; Minářová, J. Limits of Precipitation Nowcasting by Extrapolation of Radar Reflectivity for Warm Season in Central Europe. Atmos. Res. 2018, 213, 288-301. [CrossRef]

106. Germann, U.; Zawadzki, I. Scale Dependence of the Predictability of Precipitation from Continental Radar Images. Part II: Probability Forecasts. J. Appl. Meteor. 2004, 43, 74-89. [CrossRef]

107. Seed, A.W. A Dynamic and Spatial Scaling Approach to Advection Forecasting. J. Appl. Meteor. 2003, 42, 381-388. [CrossRef]

108. Foresti, L.; Reyniers, M.; Seed, A.; Delobbe, L. Development and Verification of a Real-Time Stochastic Precipitation Nowcasting System for Urban Hydrology in Belgium. Hydrol. Earth Syst. Sci. 2016, 20, 505-527. [CrossRef]

109. Schmid, W.; Mecklenburg, S.; Joss, J. Short-Term Risk Forecasts of Severe Weather. Phys. Chem. Earth Part B 2000, 25, 1335-1338. [CrossRef]

110. Kitzmiller, D.H. One-Hour Forecasts of Radar-Estimated Rainfall by an Extrapolative-Statistical Method; TDL Office Note 96-1; U.S. Department of Commerce: Washington, DC, USA; National Weather Service: Silver Spring, MD, USA; NOAA: Washington, DC, USA, 1996.

111. Pop, L.; Sokol, Z.; Minářová, J. Nowcasting of the Probability of Accumulated Precipitation Based on the Radar Echo Extrapolation. Atmos. Res. 2019, 216, 1-10. [CrossRef]

112. Bowler, N.E.; Pierce, C.E.; Seed, A.W. STEPS: A Probabilistic Precipitation Forecasting Scheme Which Merges an Extrapolation Nowcast with Downscaled NWP. Q. J. R. Meteorol. Soc. 2007, 132, 2127-2155. [CrossRef]

113. Atencia, A.; Zawadzki, I. A Comparison of Two Techniques for Generating Nowcasting Ensembles. Part I: Lagrangian Ensemble Technique. Mon. Weather Rev. 2014, 142, 4036-4052. [CrossRef]

114. Berenguer, M.; Sempere-Torres, D.; Pegram, G.G.S. SBMcast-An Ensemble Nowcasting Technique to Assess the Uncertainty in Rainfall Forecasts by Lagrangian Extrapolation. J. Hydrol. 2011, 404, 226-240. [CrossRef]

115. Pegram, G.; Clothier, A. Downscaling Rainfields in Space and Time, Using the String of Beads Model in Time Series Mode. Hydrol. Earth Syst. Sci. 2001, 5. [CrossRef]

116. Panziera, L.; Germann, U.; Gabella, M.; Mandapaka, P.V. NORA-Nowcasting of Orographic Rainfall by Means of Analogues. Q. J. R. Meteorol. Soc. 2011, 137, 2106-2123. [CrossRef]

117. Atencia, A.; Zawadzki, I. A Comparison of Two Techniques for Generating Nowcasting Ensembles. Part II: Analogs Selection and Comparison of Techniques. Mon. Wea. Rev. 2015, 143, 2890-2908. [CrossRef]

118. Pulkkinen, S.; Nerini, D.; Pérez Hortal, A.A.; Velasco-Forero, C.; Seed, A.; Germann, U.; Foresti, L. Pysteps: An Open-Source Python Library for Probabilistic Precipitation Nowcasting (v1.0). Geosci. Model Dev. 2019, 12, 4185-4219. [CrossRef]

119. Sokol, Z.; Mejsnar, J.; Pop, L.; Bližňák, V. Probabilistic Precipitation Nowcasting Based on an Extrapolation of Radar Reflectivity and an Ensemble Approach. Atmos. Res. 2017, 194, 245-257. [CrossRef]

120. Huynh, H.T.; Lai, V.S.; Soumaré, I. Stochastic Simulation and Applications in Finance with MATLAB Programs; Wiley Finance; John Wiley \& Sons: Chichester, UK; Hoboken, NJ, USA, 2008; ISBN 978-0-470-72538-2.

121. Kotsuki, S.; Kurosawa, K.; Otsuka, S.; Terasaki, K.; Miyoshi, T. Global Precipitation Forecasts by Merging Extrapolation-Based Nowcast and Numerical Weather Prediction with Locally Optimized Weights. Weather Forecast. 2019, 34, 701-714. [CrossRef]

122. Wilks, D.S. Statistical Methods in the Atmospheric Sciences; Academic Press: Cambridge, MA, USA, 2011; ISBN 978-0-12-385022-5. 
123. Lin, C.; Vasić, S.; Kilambi, A.; Turner, B.; Zawadzki, I. Precipitation Forecast Skill of Numerical Weather Prediction Models and Radar Nowcasts. Geophys. Res. Lett. 2005, 32. [CrossRef]

124. Golding, B.W. Nimrod: A System for Generating Automated Very Short Range Forecasts. Meteorol. Appl. 1998, 5, 1-16. [CrossRef]

125. Mai, X.; Zhong, H.; Li, L. Using SVM to Provide Precipitation Nowcasting Based on Radar Data. In Proceedings of the Advances in Natural Computation, Fuzzy Systems and Knowledge Discovery; Liu, Y., Wang, L., Zhao, L., Yu, Z., Eds.; Springer International Publishing: Cham, Switherlands, 2020; pp. 349-356.

126. He, J.; Chen, K.; Chen, J.; Xu, W.; Tang, L.; Liu, J. A Multi Time Scales SVM Method for Local Short Term Rainfall Prediction. Meteorology 2017, 43, 402-412. [CrossRef]

127. Liu, Y.; Lipo, W.; Zhao, L.; Yu, Z. Advances in Natural Computation, Fuzzy Systems and Knowledge Discovery: Volume 2; Advances in Intelligent Systems and Computing; Springer International Publishing: Berlin/Heidelberg, Germany, 2020; ISBN 978-3-030-325909 .

128. Huang, D.-S.; Bevilacqua, V.; Premaratne, P.; Gupta, P. Intelligent Computing Theories and Application. In Proceedings of the 14th International Conference, ICIC 2018, Wuhan, China, 15-18 August 2018; Springer: Berlin/Heidelberg, Germany, 2018; ISBN 978-3-319-95930-6.

129. Samsi, S.; Mattioli, C.J.; Veillette, M.S. Distributed Deep Learning for Precipitation Nowcasting. In Proceedings of the HPEC 2019 The IEEE High Performance Extreme Computing Conference, Boston, MA, USA, 17 May-1 June 2019. [CrossRef]

130. Shi, X.; Chen, Z.; Wang, H.; Yeung, D.-Y.; Wong, W.; WOO, W. Convolutional LSTM Network: A Machine Learning Approach for Precipitation Nowcasting. In Advances in Neural Information Processing Systems 28; Cortes, C., Lawrence, N.D., Lee, D.D., Sugiyama, M., Garnett, R., Eds.; Curran Associates Inc.: Red Hook, NY, USA, 2015; pp. 802-810.

131. Ahijevych, D.; Pinto, J.O.; Williams, J.K.; Steiner, M. Probabilistic Forecasts of Mesoscale Convective System Initiation Using the Random Forest Data Mining Technique. Weather Forecast. 2016, 31, 581-599. [CrossRef]

132. Pierce, C.E.; Hardaker, P.J.; Collier, C.G.; Haggett, C.M. GANDOLF: A System for Generating Automated Nowcasts of Convective Precipitation. Meteorol. Appl. 2000, 7, 341-360. [CrossRef]

133. Roberts, R.D.; Burgess, D.; Meister, M. Developing Tools for Nowcasting Storm Severity. Weather Forecast. 2006, 21, 540-558. [CrossRef]

134. Liu, X.; Zhou, K.; Lan, Y.; Mao, X.; Trapp, R.J. On the Construction Principle of Conceptual Models for Severe Convective Weather Forecasting Operations in China. Weather Forecast. 2020, 35, 299-308. [CrossRef]

135. Ba, M.; Xin, L.; Crockett, J.; Smith, S.B. Evaluation of NCAR's AutoNowCaster for Operational Application within the National Weather Service. Weather Forecast. 2017, 32, 1477-1490. [CrossRef]

136. Mueller, C.; Saxen, T.; Roberts, R.; Wilson, J.; Betancourt, T.; Dettling, S.; Oien, N.; Yee, J. NCAR Auto-Nowcast System. Weather Forecast. 2003, 18, 545-561. [CrossRef]

137. Ducrocq, V.; Lapore, J.-P.; Redelsperger, J.-L.; Orain, F. Initialization of a Fine-Scale Model for Convective-System Prediction: A Case Study. Q. J. R. Meteorol. Soc. 2000, 126, 3041-3065. [CrossRef]

138. Zhang, F.; Snyder, C.; Sun, J. Impacts of Initial Estimate and Observation Availability on Convective-Scale Data Assimilation with an Ensemble Kalman Filter. Mon. Weather Rev. 2004, 132, 1238-1253. [CrossRef]

139. Gustafsson, N.; Janjić, T.; Schraff, C.; Leuenberger, D.; Weissmann, M.; Reich, H.; Brousseau, P.; Montmerle, T.; Wattrelot, E.; Bučánek, A.; et al. Survey of Data Assimilation Methods for Convective-Scale Numerical Weather Prediction at Operational Centres. Q. J. R. Meteorol. Soc. 2018, 144, 1218-1256. [CrossRef]

140. Holton, J.R. An Introduction to Dynamic Meteorology, 2nd ed.; Academic Press: New York, NY, USA, 1992; ISBN 978-0-12-354360-8.

141. Leuenberger, D.; Rossa, A. Revisiting the Latent Heat Nudging Scheme for the Rainfall Assimilation of a Simulated Convective Storm. Meteorol. Atmos. Phys. 2007, 98, 195-215. [CrossRef]

142. Stephan, K.; Klink, S.; Schraff, C. Assimilation of Radar-Derived Rain Rates into the Convective-Scale Model COSMO-DE at DWD. Q. J. R. Meteorol. Soc. 2008, 134, 1315-1326. [CrossRef]

143. Jones, C.D.; Macpherson, B. A Latent Heat Nudging Scheme for the Assimilation of Precipitation Data into an Operational Mesoscale Model. Meteorol. Appl. 1997, 4, 269-277. [CrossRef]

144. Falkovich, A.; Kalnay, E.; Lord, S.; Mathur, M.B. A New Method of Observed Rainfall Assimilation in Forecast Models. J. Appl. Meteor. 2000, 39, 1282-1298. [CrossRef]

145. Sokol, Z.; Rezacova, D. Assimilation of the Radar-Derived Water Vapour Mixing Ratio into the LM COSMO Model with a High Horizontal Resolution. Atmos. Res. 2009, 92, 331-342. [CrossRef]

146. Sokol, Z. Effects of an Assimilation of Radar and Satellite Data on a Very-Short Range Forecast of Heavy Convective Rainfalls. Atmos. Res. 2009, 93, 188-206. [CrossRef]

147. Barker, D.M.; Huang, W.; Guo, Y.-R.; Bourgeois, A.J.; Xiao, Q.N. A Three-Dimensional Variational Data Assimilation System for MM5: Implementation and Initial Results. Mon. Weather Rev. 2004, 132, 897-914. [CrossRef]

148. Lewis, J.M.; Derber, J.C. The Use of Adjoint Equations to Solve a Variational Adjustment Problem with Advective Constraints. Tellus A Dyn. Meteorol. Oceanogr. 1985, 37, 309-322. [CrossRef]

149. Huang, X.-Y.; Xiao, Q.; Barker, D.M.; Zhang, X.; Michalakes, J.; Huang, W.; Henderson, T.; Bray, J.; Chen, Y.; Ma, Z.; et al. Four-Dimensional Variational Data Assimilation for WRF: Formulation and Preliminary Results. Mon. Weather Rev. 2009, 137, 299-314. [CrossRef] 
150. Evensen, G. Sequential Data Assimilation with a Nonlinear Quasi-Geostrophic Model Using Monte Carlo Methods to Forecast Error Statistics. J. Geophys. Res. Ocean. 1994, 99, 10143-10162. [CrossRef]

151. Gustafsson, N.; Bojarova, J.; Vignes, O. A Hybrid Variational Ensemble Data Assimilation for the HIgh Resolution Limited Area Model (HIRLAM). Nonlin. Process. Geophys. 2014, 21, 303-323. [CrossRef]

152. Johnson, A.; Wang, X.; Carley, J.R.; Wicker, L.J.; Karstens, C. A Comparison of Multiscale GSI-Based EnKF and 3DVar Data Assimilation Using Radar and Conventional Observations for Midlatitude Convective-Scale Precipitation Forecasts. Mon. Weather Rev. 2015, 143, 3087-3108. [CrossRef]

153. Gao, S.; Min, J. Comparison of 3DVar and EnSRF Data Assimilation Using Radar Observations for the Analysis and Prediction of an MCS. Adv. Meteorol. 2018, 2018, 1-18. [CrossRef]

154. Mazzarella, V.; Maiello, I.; Capozzi, V.; Budillon, G.; Ferretti, R. Comparison between 3D-Var and 4D-Var Data Assimilation Methods for the Simulation of a Heavy Rainfall Case in Central Italy. Adv. Sci. Res. 2017, 14, 271-278. [CrossRef]

155. Gao, J.; Stensrud, D.J. Assimilation of Reflectivity Data in a Convective-Scale, Cycled 3DVAR Framework with Hydrometeor Classification. J. Atmos. Sci. 2012, 69, 1054-1065. [CrossRef]

156. Dowell, D.C.; Wicker, L.J.; Snyder, C. Ensemble Kalman Filter Assimilation of Radar Observations of the 8 May 2003 Oklahoma City Supercell: Influences of Reflectivity Observations on Storm-Scale Analyses. Mon. Weather Rev. 2011, 139, 272-294. [CrossRef]

157. Snook, N.; Xue, M.; Jung, Y. Analysis of a Tornadic Mesoscale Convective Vortex Based on Ensemble Kalman Filter Assimilation of CASA X-Band and WSR-88D Radar Data. Mon. Weather Rev. 2011, 139, 3446-3468. [CrossRef]

158. Yussouf, N.; Stensrud, D.J. Comparison of Single-Parameter and Multiparameter Ensembles for Assimilation of Radar Observations Using the Ensemble Kalman Filter. Mon. Weather Rev. 2012, 140, 562-586. [CrossRef]

159. Sun, J.; Crook, N.A. Dynamical and Microphysical Retrieval from Doppler Radar Observations Using a Cloud Model and Its Adjoint. Part I: Model Development and Simulated Data Experiments. J. Atmos. Sci. 1997, 54, 1642-1661. [CrossRef]

160. Caya, A.; Sun, J.; Snyder, C. A Comparison between the 4DVAR and the Ensemble Kalman Filter Techniques for Radar Data Assimilation. Mon. Weather Rev. 2005, 133, 3081-3094. [CrossRef]

161. Chandrasekar, V.; Lim, S.; Bharadwaj, N.; Li, W.; McLaughlin, D.; Bringi, V.N.; Gorgucci, E. Principles of Networked Weather Radar Operation at Attenuating Frequencies. In Proceedings of the ERAD, Visby, Island of Gotland, Sweeden, 6-10 September 2004; pp. 109-114.

162. Wang, Y.; Wang, X. Direct Assimilation of Radar Reflectivity without Tangent Linear and Adjoint of the Nonlinear Observation Operator in the GSI-Based EnVar System: Methodology and Experiment with the 8 May 2003 Oklahoma City Tornadic Supercell. Mon. Weather Rev. 2017, 145, 1447-1471. [CrossRef]

163. Duda, J.D.; Wang, X.; Wang, Y.; Carley, J.R. Comparing the Assimilation of Radar Reflectivity Using the Direct GSI-Based Ensemble-Variational (EnVar) and Indirect Cloud Analysis Methods in Convection-Allowing Forecasts over the Continental United States. Mon. Weather Rev. 2019, 147, 1655-1678. [CrossRef]

164. James, C.; Houze, R.A. A Real-Time Four-Dimensional Doppler Dealiasing Scheme. J. Atmos. Ocean. Technol. 2001, 18, 1674-1683. [CrossRef]

165. Xu, Q.; Nai, K.; Liu, S.; Karstens, C.; Smith, T.; Zhao, Q. Improved Doppler Velocity Dealiasing for Radar Data Assimilation and Storm-Scale Vortex Detection. Adv. Meteorol. 2013, 2013, 1-10. [CrossRef]

166. He, G.; Sun, J.; Ying, Z.; Zhang, L. A Radar Radial Velocity Dealiasing Algorithm for Radar Data Assimilation and Its Evaluation with Observations from Multiple Radar Networks. Remote Sens. 2019, 11, 2457. [CrossRef]

167. Kato, R.; Shimizu, S.; Shimose, K.; Iwanami, K. Storm, Flood and Landslide Research Division, National Research Institute for Earth Science and Disaster Resilience (NIED) 3-1 Tennodai, Tsukuba, Ibaraki 305-0006, Japan Very Short Time Range Forecasting Using CReSS-3DVAR for a Meso- $\gamma$-Scale, Localized, Extremely Heavy Rainfall Event: Comparison with an Extrapolation-Based Nowcast. J. Disaster Res. 2017, 12, 967-979. [CrossRef]

168. Zhang, L.; Tian, X.; Zhang, H. Application of Multigrid NLS-4DVar in Radar Radial Velocity Data Assimilation with WRF-ARW. Atmos. Ocean. Sci. Lett. 2019, 12, 409-416. [CrossRef]

169. Zhang, B.; Tian, X.; Sun, J.; Chen, F.; Zhang, Y.; Zhang, L.; Fu, S. PODEn4DVar-Based Radar Data Assimilation Scheme: Formulation and Preliminary Results from Real-Data Experiments with Advanced Research WRF (ARW). Tellus A Dyn. Meteorol. Oceanogr. 2015, 67, 26045. [CrossRef]

170. Snyder, C.; Zhang, F. Assimilation of Simulated Doppler Radar Observations with an Ensemble Kalman Filter. Mon. Weather Rev. 2003, 131, 1663-1677. [CrossRef]

171. Chen, Y.; Snyder, C. Assimilating Vortex Position with an Ensemble Kalman Filter. Mon. Weather Rev. 2007, 135, 1828-1845. [CrossRef]

172. Zeng, Y.; Janjić, T.; de Lozar, A.; Welzbacher, C.A.; Blahak, U.; Seifert, A. Assimilating Radar Radial Wind and Reflectivity Data in an Idealized Setup of the COSMO-KENDA System. Atmos. Res. 2021, 249, 105282. [CrossRef]

173. Seo, D.-J.; Habib, E.; Andrieu, H.; Morin, E. Hydrologic Applications of Weather Radar. J. Hydrol. 2015, 531, 231-233. [CrossRef]

174. Berne, A.; Krajewski, W.F. Radar for Hydrology: Unfulfilled Promise or Unrecognized Potential? Adv. Water Resour. 2013, 51, 357-366. [CrossRef]

175. Loumagne, C.; Normand, M.; Riffard, M.; Weisse, A.; Quesney, A.; Hégarat-Mascle, S.L.; Alem, F. Integration of Remote Sensing Data into Hydrological Models for Reservoir Management. Hydrol. Sci. J. 2001, 46, 89-102. [CrossRef] 
176. Loritz, R.; Hrachowitz, M.; Neuper, M.; Zehe, E. The Role and Value of Distributed Precipitation Data for Hydrological Models. Hydrol. Earth Syst. Sci. 2020, 25, 147-167. [CrossRef]

177. Li, Y.; Grimaldi, S.; Walker, J.P.; Pauwels, V.R.N. Application of Remote Sensing Data to Constrain Operational Rainfall-Driven Flood Forecasting: A Review. Remote Sens. 2016, 8, 456. [CrossRef]

178. Ridler, M.-E.; Madsen, H.; Stisen, S.; Bircher, S.; Fensholt, R. Assimilation of SMOS-Derived Soil Moisture in a Fully Integrated Hydrological and Soil-Vegetation-Atmosphere Transfer Model in Western Denmark. Water Resour. Res. 2014, 50, 8962-8981. [CrossRef]

179. Gabriele, S.; Chiaravalloti, F.; Procopio, A. Radar-Rain-Gauge Rainfall Estimation for Hydrological Applications in Small Catchments. In Proceedings of the Advances in Geosciences, Fargau-Pratjau, Germany, 12 July 2017; Volume 44, pp. 61-66.

180. Delrieu, G.; Braud, I.; Berne, A.; Borga, M.; Boudevillain, B.; Fabry, F.; Freer, J.; Gaume, E.; Nakakita, E.; Seed, A.; et al. Weather Radar and Hydrology. Adv. Water Resour. 2009, 32, 969-974. [CrossRef]

181. Mosavi, A.; Ozturk, P.; Chau, K. Flood Prediction Using Machine Learning Models: Literature Review. Water 2018, $10,1536$. [CrossRef]

182. Dinu, C.; Drobot, R.; Pricop, C.; Blidaru, T.V. Genetic Programming Technique Applied for Flash-Flood Modelling Using Radar Rainfall Estimates. Math. Model. Civ. Eng. 2017, 13, 27-38. [CrossRef]

183. Orellana-Alvear, J.; Célleri, R.; Rollenbeck, R.; Muñoz, P.; Contreras, P.; Bendix, J. Assessment of Native Radar Reflectivity and Radar Rainfall Estimates for Discharge Forecasting in Mountain Catchments with a Random Forest Model. Remote Sens. 2020, 12, 1986. [CrossRef]

184. Kratzert, F.; Klotz, D.; Brenner, C.; Schulz, K.; Herrnegger, M. Rainfall-Runoff Modelling Using Long Short-Term Memory (LSTM) Networks. Hydrol. Earth Syst. Sci. 2018, 22, 6005-6022. [CrossRef]

185. Xiang, Z.; Demir, I. Distributed Long-Term Hourly Streamflow Predictions Using Deep Learning-A Case Study for State of Iowa. Environ. Model. Softw. 2020, 131, 104761. [CrossRef]

186. Smith, P.J.; Panziera, L.; Beven, K.J. Forecasting Flash Floods Using Data-Based Mechanistic Models and NORA Radar Rainfall Forecasts. Hydrol. Sci. J. 2014, 59, 1403-1417. [CrossRef]

187. Borga, M. Accuracy of Radar Rainfall Estimates for Streamflow Simulation. J. Hydrol. 2002, 267, 26-39. [CrossRef]

188. Seo, B.-C.; Krajewski, W.F.; Quintero, F.; ElSaadani, M.; Goska, R.; Cunha, L.K.; Dolan, B.; Wolff, D.B.; Smith, J.A.; Rutledge, S.A.; et al. Comprehensive Evaluation of the IFloodS Radar Rainfall Products for Hydrologic Applications. J. Hydrometeor. 2018, 19, 1793-1813. [CrossRef]

189. Cecinati, F.; Rico-Ramirez, M.A.; Heuvelink, G.B.M.; Han, D. Representing Radar Rainfall Uncertainty with Ensembles Based on a Time-Variant Geostatistical Error Modelling Approach. J. Hydrol. 2017, 548, 391-405. [CrossRef]

190. Dai, Q.; Han, D.; Zhuo, L.; Huang, J.; Islam, T.; Srivastava, P.K. Impact of Complexity of Radar Rainfall Uncertainty Model on Flow Simulation. Atmos. Res. 2015, 161-162, 93-101. [CrossRef]

191. Beven, K.; Binley, A. The Future of Distributed Models: Model Calibration and Uncertainty Prediction. Hydrol. Process. 1992, 6, 279-298. [CrossRef]

192. Poméon, T.; Wagner, N.; Furusho, C.; Kollet, S.; Reinoso-Rondinel, R. Performance of a PDE-Based Hydrologic Model in a Flash Flood Modeling Framework in Sparsely-Gauged Catchments. Water 2020, 12, 2157. [CrossRef]

193. Seo, B.-C.; Cunha, L.K.; Krajewski, W.F. Uncertainty in Radar-Rainfall Composite and Its Impact on Hydrologic Prediction for the Eastern Iowa Flood of 2008. Water Resour. Res. 2013, 49, 2747-2764. [CrossRef]

194. Paz, I.; Tchiguirinskaia, I.; Schertzer, D. Rain Gauge Networks' Limitations and the Implications to Hydrological Modelling Highlighted with a X-Band Radar. J. Hydrol. 2020, 583, 124615. [CrossRef]

195. Zhu, D.H.; Peng, D.Z.; Cluckie, I.D. Statistical Analysis of Error Propagation from Radar Rainfall to Hydrological Models. Hydrol. Earth Syst. Sci. Discuss. 2012, 9, 10277-10302. [CrossRef]

196. Sikorska, A.E.; Seibert, J. Value of Different Precipitation Data for Flood Prediction in an Alpine Catchment: A Bayesian Approach. J. Hydrol. 2018, 556, 961-971. [CrossRef]

197. Shakti, P.C.; Tsuyoshi, N.; Ryohei, M. The Role of the Spatial Distribution of Radar Rainfall on Hydrological Modeling for an Urbanized River Basin in Japan. Water 2019, 11, 1703. [CrossRef]

198. Paz, I.; Willinger, B.; Gires, A.; Alves de Souza, B.; Monier, L.; Cardinal, H.; Tisserand, B.; Tchiguirinskaia, I.; Schertzer, D. Small-Scale Rainfall Variability Impacts Analyzed by Fully-Distributed Model Using C-Band and X-Band Radar Data. Water 2019, 11, 1273. [CrossRef]

199. Anagnostou, M.N.; Nikolopoulos, E.I.; Kalogiros, J.; Anagnostou, E.N.; Marra, F.; Mair, E.; Bertoldi, G.; Tappeiner, U.; Borga, M. Advancing Precipitation Estimation and Streamflow Simulations in Complex Terrain with X-Band Dual-Polarization Radar Observations. Remote Sens. 2018, 10, 1258. [CrossRef]

200. Cristiano, E.; ten Veldhuis, M.-C.; van de Giesen, N. Spatial and Temporal Variability of Rainfall and Their Effects on Hydrological Response in Urban Areas-A Review. Hydrol. Earth Syst. Sci. 2017, 21, 3859-3878. [CrossRef]

201. Cristiano, E.; Veldhuis, M.; Wright, D.B.; Smith, J.A.; van de Giesen, N. The Influence of Rainfall and Catchment Critical Scales on Urban Hydrological Response Sensitivity. Water Resour. Res. 2019, 55, 3375-3390. [CrossRef]

202. Lobligeois, F.; Andréassian, V.; Perrin, C.; Tabary, P.; Loumagne, C. When Does Higher Spatial Resolution Rainfall Information Improve Streamflow Simulation? An Evaluation Using 3620 Flood Events. Hydrol. Earth Syst. Sci. 2014, 18, 575-594. [CrossRef] 
203. Ochoa-Rodriguez, S.; Wang, L.-P.; Willems, P.; Onof, C. A Review of Radar-Rain Gauge Data Merging Methods and Their Potential for Urban Hydrological Applications. Water Resour. Res. 2019, 55, 6356-6391. [CrossRef]

204. McKee, J.L.; Binns, A.D. A Review of Gauge-Radar Merging Methods for Quantitative Precipitation Estimation in Hydrology. Can. Water Resour. J./Rev. Can. Des Ressour. Hydr. 2016, 41, 186-203. [CrossRef]

205. Jadidoleslam, N.; Mantilla, R.; Krajewski, W.F.; Goska, R. Investigating the Role of Antecedent SMAP Satellite Soil Moisture, Radar Rainfall and MODIS Vegetation on Runoff Production in an Agricultural Region. J. Hydrol. 2019, 579, 124210. [CrossRef]

206. Heuvelink, D.; Berenguer, M.; Brauer, C.C.; Uijlenhoet, R. Hydrological Application of Radar Rainfall Nowcasting in The Netherlands. Environ. Int. 2020, 136, 105431. [CrossRef]

207. Yu, W.; Nakakita, E.; Kim, S.; Yamaguchi, K. Improvement of Rainfall and Flood Forecasts by Blending Ensemble NWP Rainfall with Radar Prediction Considering Orographic Rainfall. J. Hydrol. 2015, 531, 494-507. [CrossRef]

208. Alfieri, L.; Berenguer, M.; Knechtl, V.; Liechti, K.; Sempere-Torres, D.; Zappa, M. Flash Flood Forecasting Based on Rainfall Thresholds. In Handbook of Hydrometeorological Ensemble Forecasting; Duan, Q., Pappenberger, F., Thielen, J., Wood, A., Cloke, H.L., Schaake, J.C., Eds.; Springer: Berlin/Heidelberg, Germany, 2016; pp. 1-38. ISBN 978-3-642-40457-3.

209. Bouilloud, L.; Delrieu, G.; Boudevillain, B.; Kirstetter, P.-E. Radar Rainfall Estimation in the Context of Post-Event Analysis of Flash-Flood Events. J. Hydrol. 2010, 394, 17-27. [CrossRef]

210. Marchi, L.; Borga, M.; Preciso, E.; Gaume, E. Characterisation of Selected Extreme Flash Floods in Europe and Implications for Flood Risk Management. J. Hydrol. 2010, 394, 118-133. [CrossRef]

211. Bronstert, A.; Agarwal, A.; Boessenkool, B.; Crisologo, I.; Fischer, M.; Heistermann, M.; Köhn-Reich, L.; López-Tarazón, J.A.; Moran, T.; Ozturk, U.; et al. Forensic Hydro-Meteorological Analysis of an Extreme Flash Flood: The 2016-05-29 Event in Braunsbach, SW Germany. Sci. Total Environ. 2018, 630, 977-991. [CrossRef] [PubMed]

212. Borga, M.; Comiti, F.; Ruin, I.; Marra, F. Forensic Analysis of Flash Flood Response. Wires Water 2019, 6, e1338. [CrossRef]

213. Borga, M.; Gaume, E.; Creutin, J.D.; Marchi, L. Surveying Flash Floods: Gauging the Ungauged Extremes. Hydrol. Process. 2008, 22, 3883-3885. [CrossRef]

214. Javelle, P.; Demargne, J.; Defrance, D.; Pansu, J.; Arnaud, P. Evaluating Flash-Flood Warnings at Ungauged Locations Using Post-Event Surveys: A Case Study with the AIGA Warning System. Hydrol. Sci. J. 2014, 59, 1390-1402. [CrossRef]

215. Borga, M.; Stoffel, M.; Marchi, L.; Marra, F.; Jakob, M. Hydrogeomorphic Response to Extreme Rainfall in Headwater Systems: Flash Floods and Debris Flows. J. Hydrol. 2014, 518, 194-205. [CrossRef] 